\title{
EL CÓLERA EN ESPAÑA (1854-1856). ALGUNAS CONSIDERACIONES LEGALES, SANITARIAS, SOCIALES, ECONÓMICAS Y DEMOGRÁFICAS
}

\author{
Rafael Luis Pérez Díaz \\ I.E.S. José de Churriguera (Leganés) \\ historiachurriguera@gmail.com
}

RESUMEN: El presente trabajo estudia, a partir de diversas fuentes primarias y secundarias, la epidemia de cólera que invadió España desde finales de 1853 hasta 1856. Trata diferentes aspectos: socioeconómicos como la financiación de la lucha contra la enfermedad, que recayó fundamentalmente en las autoridades locales, teniendo gran importancia la solidaridad económica de muchos ciudadanos; legales como la normativa que regulaba la movilidad en tiempo de epidemia. Analiza el papel de las Juntas de Sanidad y Beneficencia como principal herramienta de actuación no sólo sanitaria sino también social. Trata fenómenos sociales como la huida, especialmente de las élites socioeconómicas, de las localidades infectadas. Examina la influencia de algunas consideraciones morales sobre cuestiones puramente sanitarias. Por último, incluye las cifras oficiales de contagiados y fallecidos, con un análisis de las razones explican por qué deben ser revisadas al alza.

Palabras clave: epidemia, cólera, gasto público, Juntas de Sanidad, Bienio Progresista.

\section{CHOLERA IN SPAIN (1854-1856). SOME LEGAL, HEALTH, SOCIAL, ECONOMIC AND DEMOGRAPHIC CONSIDERATIONS}

\begin{abstract}
This work studies the cholera disease that invaded Spain from the end of 1853 to 1856 . Focusing on socio-economic aspects such as the funding of the fight against the cholera disease, that fell on local authorities mainly,
\end{abstract}


and the most important was the economic solidarity of many citizens. It studies the role of the "Juntas de Salud y Beneficiencia" as main instrument not only medical but also social. Social phenomena as the social-economic elite fled from the affected areas. And the influence of morality over health issues. At last, there is an analysis report of the official numbers of infected and deceased people, with the reasons that explain why they must revise upwards.

Keywords: Epidemic, cholera disease, public spending, Health boards, Progressive Biennium.

Recibido: 3 de mayo de 2021

Aceptado: 6 de octubre de 2021

\section{Introducción: la epidemia}

A finales de 1853 la España peninsular, además de los archipiélagos canario y balear, se había visto libre de la epidemia de cólera que desde el año anterior asolaba varios países de distintos continentes. Desgraciadamente no había corrido la misma suerte Cuba, en donde la enfermedad estaba instalada desde 1850 causando una importante mortalidad, solo del 15 de septiembre al 15 de octubre habían fallecido en la isla por cólera morboasiático 742 personas de las 1315 enfermas ${ }^{1}$. Aunque la epidemia seguía causando estragos en algunos países del norte de Europa, como Suecia, con miles de muertes; de otros Ilegaban noticias alentadoras, por ejemplo, se daba por desaparecido el cólera morbo-asiático en los Países Bajos². Las preocupaciones de las autoridades sanitarias españolas eran otras, como las fiebres tifoideas, que solo en 4 municipios gallegos (Santiago de Compostela, Noya, Arzúa y Betanzos) en el año que terminaba habían acabado con la vida de 947 personas $^{3}$.

No obstante, la amenaza del cólera no dejaba de estar presente, en la memoria colectiva tenía que pesar lo ocurrido durante la epidemia que comenzó en 1833. Una Real Orden del Ministerio de la Gobernación (8 de septiembre de 1853), dirigida al Director General de Beneficencia y Sanidad, trataba el asunto estableciendo medidas preventivas para evitar la posible extensión de la enfermedad en caso de que llegase a España. Esta R. Orden, igual que la legislación sanitaria inmediatamente anterior, estaba muy influida por la corriente higienista que se preocupaba por las condiciones de higiene de las viviendas y

1. El Siglo Médico, 1 de enero 1854.

2. Parte oficial de 27 de diciembre de 1854. Boletín Oficial de la Provincia de Guadalajara de 4 de enero de 1854.

3. El Siglo Médico, 28 de mayo de 1854. El desglose de fallecidos por municipios ese el siguiente: Santiago 294, Noya 116, Arzúa 343 y Betanzos 194. 
lugares de trabajo de los más pobres ${ }^{4}$. Las instrucciones, poco concretas y sin plazo de ejecución, se limitaban fundamentalmente a recomendar unas simples medidas higiénicas. Algunas de las recomendaciones eran de carácter colectivo como que los cebaderos tenían que situarse fuera de los núcleos de población, que se limpiasen las calles, que se evitaran las aguas estancadas en los pueblos o que se vigilasen los artículos de primera necesidad que se vendían; otras medidas eran de tipo individual como la recomendación mayor limpieza personal, la renovación de ropa de cama, el aireado de las habitaciones..., en las dependencias del Estado en donde se congregase un número importante de personas, tales como cuarteles, maestranzas, colegios, conventos o fábricas. Tampoco concretaba más en cómo se organizaría la asistencia sanitaria en caso de que se presentase la epidemia, simplemente que era necesario excogitar (sic) recursos para tener un buen sistema de atención hospitalaria y domiciliaria, pero no había ninguna dotación presupuestaria. Como se dice en la R.O.: lo que fundamentalmente hacía el gobierno era "fiar en el divino auxilio para evitar el mal o amenguar sus estragos"

En 1854 no habría tanta suerte, el cólera se instaló en España, causando una epidemia que de forma recurrente atacó a gran parte del país. De inmediato el problema generó una abundante bibliografía, centrada fundamentalmente en determinar su origen, las causas de su expansión y los posibles remedios. También hubo algunos estudios locales, por ejemplo, en Jaén o Gerona, sobre la incidencia de la epidemia y una obra de 1858: "Memoria Histórica del cólera morbo-asiático en España" de Mariano González de Samano, monumental por su extensión de más de 1200 páginas divididas en 2 tomos, que estudia el origen, expansión y causas de la enfermedad desde diversos ángulos. Carecemos de un trabajo reciente que estudie la epidemia en toda España, pero contamos con una veintena de estudios locales, que abordan el tema con enfoques diversos. Estos trabajos, junto con las fuentes primarias (prensa, memorias de las Juntas de Sanidad...), han servido para extraer conclusiones generales sobre cómo se actuó en ese convulso periodo; la aparición de nuevos estudios locales podrá ayudar a corroborar o a matizar dichas conclusiones.

El 19 de noviembre de 1853 el Isabel la Católica, vapor correo con La Habana, llegó al puerto de Vigo con 3 enfermos de cólera, por lo que fue derivado al lazareto de la isla de San Simón ${ }^{6}$. Las malas condiciones del lazareto propiciaron la extensión de la enfermedad; la isla carecía de agua potable teniendo que recibirla de Redondela, localidad a la que se llevaban a lavar las ropas de sanos

4. Diego José FERIA LORENZO: “La primera regulación sanitaria en España: la Ley Orgánica de 1855", Revista de Historia das Ideias, 33 (2012), pp. 217-239.

5. Boletín Oficial de la Provincia de Madrid $n^{\circ}$ 4787, 12 de noviembre de 1843.

6. La atribución del origen de la enfermedad al buque correo Isabel la Católica se repite de forma sistemática en la prensa, así lo recogen por ejemplo El Siglo Médico, 15 de enero de 1854, y El Genio de la libertad, 19 de enero de 1854. 
y enfermos ${ }^{7}$. A los pocos días de llegar el barco tanto en Redondela como en las cercanas parroquias de Cedeira y Cesantes, que se surtían de agua en donde se lavaban las ropas, comenzaron a enfermar algunas personas con síntomas como vómitos, diarreas y calambres, rápidamente la enfermedad se fue extendiendo a otras localidades pontevedresas.

No es posible cuantificar de forma precisa la mortalidad que provocó la enfermedad en esos momentos iniciales, solo disponemos de datos parciales publicados por la prensa. Del 10 al 18 de diciembre fallecieron en la provincia de Pontevedra por el entonces llamado "cólico de las ostras" 27 personas ${ }^{8}$.

Durante el año 1854 la epidemia se extendió por todo el país; al foco inicial gallego hubo que sumar otro posterior en Barcelona, que muy probablemente tuvo su origen en un buque procedente de Marsella. A principios del mes de enero de 1855 la epidemia parecía extinguida, pero en febrero la enfermedad reapareció, primero por Cartaya (Huelva), pero también en localidades de las provincias de Zaragoza, Málaga, Granada y Zamora; de nuevo toda la Península sufrió los embates del cólera ${ }^{9}$. El proceso se repitió, cuando ya parecía que el cólera había desaparecido de España, a finales de enero de 1856 nuevamente en Cartaya se reavivó, probablemente importado de Portugal. Por fortuna la extensión de la enfermedad fue menor, viéndose afectadas una veintena de provincias, la última Salamanca, en dónde se desató en el mes de octubre. A comienzos de enero de 1857 ya no quedaba ninguna localidad española invadida por el cólera ${ }^{10}$

\section{No es cólera: la negación de la epidemia}

El primer problema fue identificar la enfermedad ya que entraban en juego no solo cuestiones sanitarias, también lo hacían intereses económicos y políti-

7. El lazareto de San Simón, construido en la ría de Vigo en las islas de San Simón y San Antón unidas por un puente, era relativamente nuevo, se había dispuesto su construcción por Real Orden de 6 de junio de 1838 y se declaró en funcionamiento por R.O de 1 de junio de 1842. Su función era que se hiciesen allí las cuarentenas de los barcos procedentes del norte de Europa y el Caribe. La instalación sufría una grave carencia: no contaba con agua potable. El problema sanitario provocado por el Isabel la Católica hizo que el gobierno nombrase una comisión interministerial formada por 3 personas, como presidente ejercía el doctor en medicina Pedro Felipe Monlau, vocal supernumerario del Consejo de Sanidad, como secretario se designó a Luciano Marín, auxiliar del Ministerio de la Gobernación, completaba la comisión un ingeniero nombrado por el Ministerio de Fomento ; la conclusión fue tajante: el lazareto de San Simón no servía para la función encomendada, no obstante no dejó de utilizarse hasta 1923.

8. El Siglo Médico, 8 de enero de 1854.

9. Mariano GONZÁLEZ DE SAMANO: Memoria Histórica del cólera morbo-asiático en España. Vol. II, Madrid, Imprenta de Manuel Álvarez, 1858, pp. 308-310.

10. Ibid., pp. 322-325. 
cos. La declaración de Vigo como "puerto sucio" suponía un grave quebranto económico para la ciudad y toda su comarca, como evidenció que el puerto de Oporto decretase inmediatamente incomunicación para todos los buques que llegaran procedentes de las costas gallegas ${ }^{11}$. Eso provocó que tanto la prensa como las autoridades locales, incluidas las sanitarias, negasen la existencia del cólera e intentaran dar otra explicación a la enfermedad como el ya mencionado "cólico de las ostras", es decir los que enfermaron lo hicieron por comer marisco $^{12}$, a eso se añadía la baja extracción social de los afectados, lo que en opinión de algunos les hacía más susceptibles de sufrir dicho mal ${ }^{13}$. Desde el punto de vista sanitario esta actitud era de una gran irresponsabilidad.

El gobierno del Partido Moderado, presidido por Luis José Sartorius, primer conde de San Luis, parecía muy interesado en ocultar el origen colérico de la enfermedad; el Gobernador Civil de Pontevedra multó con 300 reales a Manuel Ocampo, cirujano de Redondela, por defender que se trataba de cólera ${ }^{14}$. Tampoco dudaba en utilizar las publicaciones oficiales con este fin, así La Gazeta de Madrid extractaba en su parte no oficial una carta publicada por El Heraldo, periódico portavoz del gobierno conservador, en la que se calificaba la información de que la enfermedad del lazareto de San Simón era cólera como una paparrucha incierta ${ }^{15}$; o el Boletín Oficial de la Provincia de Orense negaba que la enfermedad que se estaba produciendo en la provincia de Pontevedra fuese cólera y la atribuía a la miseria, la desnudez y la falta de atención médica ${ }^{16}$. También la prensa afín al gobierno, incluida la especializada en temas médicos y sanitarios como El Porvenir Médico, se sumaba a esa negación inicial: "A nadie queda duda de que no ha sido el cólera asiático la enfermedad que presentó en las inmediaciones del lazareto de Vigo, y que casi ha desaparecido..."17.

Esta situación no varió en los meses siguientes, por un lado se utilizó la censura contra la prensa que publicaba informaciones contrarias a la versión de que la enfermedad estaba totalmente controlada y casi extinguida, por ejemplo diario El Oriente vio como 2 de sus números, los del 9 y 11 de febrero de 1854, fueron denunciados por el Fiscal de Imprenta debido a las informaciones que contenían sobre la invasión del cólera en Galicia ${ }^{18}$; por otro la prensa moderada, incluida también la especializada, en línea con la actitud negacionista del gobierno, tendía a ocultar la información sobre la evolución de la enfer-

11. El Clamor Público, 12 de enero de 1854.

12. El Faro de Vigo, 5 de enero de 1854. Tomado de El Clamor Público, 14 de enero de 1854.

13. El Coruñes, 7 de enero de 1854. Tomado de El Porvenir Médico, 15 de enero de 1854.

14. El Genio de la Libertad, 22 de marzo de 1854.

15. La Gazeta de Madrid, 14 de enero de 1854.

16. Boletín Oficial de la Provincia de Orense, 7 de enero de 1854.

17. El Porvenir Médico, 20 de enero de 1854.

18. El Genio de la Libertad, 19 y 22 de marzo de 1854. 
medad, esto se explica porque a mediados del siglo XIX la prensa española era fundamentalmente prensa de partido. Lo justificaban diciendo que no querían producir una excesiva alarma ${ }^{19}$. Pero incluso podían ir más allá y defender el silencio informativo con razones supuestamente científicas, así Agustín Juderías y Corella, colaborador de El Porvenir Médico, publicó un artículo en el que calificaba al cólera que afectaba a Galicia de enfermedad "sentimental-nerviosa" (sic), y que por lo tanto se expandía debido a la consternación que producía en las personas, siendo el mejor remedio para combatirla no informar sobre ella ${ }^{20}$. Todavía no se sabía que la enfermedad está producida por la bacteria Vibrio cholerae, siendo la forma fundamental de transmisión las aguas contaminadas por las heces de alguien enfermo ${ }^{21}$; pese a que la teoría más aceptada en esos momentos era la miasmática ${ }^{22}$, que defendía que la enfermedad se transmitía a través de la atmósfera, una parte de la carrera médica compartía el argumento de que el estado anímico podía provocar una situación de debilidad ante la enfermedad propiciando su expansión, por ejemplo Ignacio Gámez y Miguel Morales, médicos en Huelma (Jaén), opinaban que además de algunos alimentos (habas, habichuelas, bacalao y ensalada de lechuga) los disgustos y la pesadumbre habían influido en las extensión de los contagios en la localidad 23; aunque en ocasiones parece que se trata de un intento de ocultar tras argumentos supuestamente médicos y científicos lo que era una decisión política que podía tener consecuencias negativas. No obstante, el silencio no fue total, solo interesado, ya que sí encontramos en la prensa moderada algunas noticias, casi siempre dando una visión positiva de la evolución de la enfermedad que, en su opinión, no solo estaba controlada, sino que además remitía permanentemente, estando a punto de desaparecer. Cuando cambió la situación política

19. El Porvenir Médico, 15 de junio de 1854.

20. El Porvenir Médico, de 31 de marzo de 1854.

Aunque minoritaria, había una corriente médica que defendía esa teoría. Mariano GONZÁLEZ DE SAMANO: Memoria Histórica del..., vol. I, p. 93, cita, además de al propio Juderías, a los médicos Espuig, Carranza, Agustín Juan y Taboada como partidarios de esta teoría, habituales colaboradores de la prensa médica (El Porvenir Médico, La Gaceta Medica, El Heraldo Médico y El Siglo Médico).

21. Ese año de 1854 fue clave para el conocimiento del origen del cólera y sus procesos de transmisión. Filippo Pacini, el 10 de diciembre, durante una sesión de la Sociedad Médico Física de Florencia, hizo público su descubrimiento de que la enfermedad era producida por una bacteria. Por otro lado, el médico británico John Snow pudo confirmar su teoría, ya avanzada por él en 1849, de que la transmisión del cólera se producía por medio de aguas contaminadas; para ello fue clave el estudio que, junto al reverendo Henry Whitehead, realizó del brote colérico surgido en torno a la londinense fuente de Broad Street durante 1854. Los descubrimientos de ambos tardaron varios años en ser aceptados por la comunidad científica.

22. Las controversias médicas sobre las teorías que explicaban la expansión de la enfermedad, ampliamente recogidas en la prensa especializada como El Siglo Médico, han sido intencionadamente obviadas por considerarse más propias de la historia de la Medicina.

23. Magdalena VALENZUELA GUZMÁN: "1855. Epidemia de cólera en Huelma. El verano del terror", Sumuntan: anuario de estudios sobre Sierra Mágina, 32 (2014), pp. 237-248. 
con la llegada de los progresistas también lo hizo la comunicativa: se mantuvo constantemente informada a la opinión pública, pero la salida de Espartero de la Jefatura del gobierno retrotrajo la información a la situación anterior, con la presidencia de $\mathrm{O}^{\prime}$ Donnell desaparecieron los partes sanitarios ${ }^{24}$.

Una reunión celebrada el 6 de enero en Tuy, a la que asistieron además de los médicos de la localidad el Gobernador Civil de Pontevedra (el mismo que había multado a Manuel Ocampo), sirvió para certificar oficialmente por primera vez que la enfermedad que se sufría en algunas localidades de la provincia era el cólera-morbo asiático ${ }^{25}$. Pero las presiones que recibió el Gobernador Civil retrasaron la toma de medidas preventivas ya que aunque había decidido declarar al puerto de Vigo como sucio tras reunirse con los miembros de la Junta de Sanidad local pospuso la declaración al 15 de ese mes, fecha en la que tampoco lo hizo ${ }^{26}$.

La negación y/o ocultación de la enfermedad por intereses locales no fue algo que sucediese solo en Vigo; la Real Orden de 26 de agosto de $1854^{27}$ al querer regular la situación la describe: había localidades en las que por intereses locales, pese a que se tenía constancia de la existencia del cólera se ocultaba, por ejemplo denominando la enfermedad de otra manera (ya se ha visto el ejemplo vigués del cólico de ostras), para seguir dando patentes limpias y mantener el comercio. Por ello ordena que se sancione a las autoridades que oculten la existencia del cólera. Durante el verano de 1854, cuando la provincia de Badajoz ya estaba sufriendo la epidemia, en los libros parroquiales de defunciones de la localidad de Zafra no aparece el término cólera por miedo a que la localidad resultase incomunicada por la enfermedad ${ }^{28}$. Muy poco tiempo después el propio gobierno, por medio de la Real Orden de 6 de septiembre de $1854^{29}$, daba una clara explicación del origen del problema: las

24. José Ramón URQUIJO Y GOITIA: "Condiciones de vida y cólera: la epidemia de 18541856 en Madrid", Estudios de Historia Social, 15 (1980), pp. 63-139.

25. El Siglo Médico, 22 de enero de 1854.

En la reunión estuvieron presentes el Dr. D. Benito Gil, subdelegado de Tuy; el de Vigo, D. Nicolás Taboada; D. Joaquín Pastor, director de los baños de Caldelas; el Dr. don Buenaventura Gassols, vocal de la junta de Sanidad; D. Antonio Noguerol, médico cirujano de la armada; D. Ramón Gómez Parcero, D. Antonio Cobian, D. Eduardo Arnies y D. Ramen Collia. Mariano GONZÁLEZ DE SAMANO: Memoria Histórica del..., vol. I, p. 283.

26. El Porvenir Médico, $\mathrm{n}^{\circ}$ 59, 25 de enero de 1854.

27. Tomada de Mariano GONZÁLEZ DE SAMANO: Memoria Histórica del..., vol. II, pp. 102-103.

28. José Luis SÁNCHEZ ÁLVAREZ, y Diego PERAL PACHECO: “La epidemia de cólera de 1855 en Olivenza", Revista de Estudios Extremeños, tomo XLV, 3 (2009), pp. 1289-1320.

29. La Real Orden de 6 de septiembre de 1854 titulada "Real orden aprobando el proyecto de reforma sanitaria remitido por el consejo de sanidad en 10 de octubre de 1853 y acordando otras disposiciones sobre el mismo ramo" es una disposición singular, empezando por su origen, que aparece en el título, se trata de un informe remitido por el Consejo de Sanidad y que el gobierno asume como propio en su totalidad. Además de tener contenido normativo incluye 
Juntas de sanidad estaban formadas además de por autoridades políticas por navieros, armadores y comerciantes que anteponían sus intereses particulares a las sanitarios por lo que ocultan y demoran el reconocimiento de la existencia del cólera en sus localidades; hasta que se pudiera aplicar la propuesta de reforma que hacía de las Juntas de Sanidad: que estuviesen formadas solo por autoridades responsables y retribuidas, la solución era aplicar con rigor la normativa, especialmente la citada R. Orden de 26 de agosto que ordenaba sancionar a las autoridades que no cumplieran con la obligación de hacer pública la declaración de la enfermedad. La actitud de anteponer los intereses económicos a los sanitarios no solo sucedía en las grandes localidades. Vicente Puyol, médico titular de Sangüesa y miembro de la Junta Municipal de sanidad se queja de la actitud de algunos componentes de la misma, a los que califica de agiotistas, que anteponen sus intereses a la opinión de los médicos, rechazando que se declare que en Sangüesa había cólera-morbo; afortunadamente en este caso las autoridades se fiaron del criterio médico ${ }^{30}$. Pero algunas de las autoridades nombradas por el gobierno incumplían sus órdenes, así el 13 de septiembre del 54 Manuel Monedero, Gobernador Civil de Jaén aseguraba que en la provincia no había casos de cólera, solo algunos cólicos producidos por comer fruta y algún otro desarreglo alimenticio ${ }^{31}$. Incluso hubo Juntas de Sanidad, como la de Valencia, que llegaban a justificar esta ocultación por considerarla positiva, ya que: "Esta ocultación que tan inmensos beneficios produjo, acarreó por ello daño alguno, ni aun exigió siquiera de parte de los apestados el más leve sacrificio" ${ }^{\prime \prime 2}$ Las presiones sobre los médicos para evitar que se declarase que una localidad estaba afectada por el cólera a veces alcanzaban niveles muy graves, como por ejemplo las que sufrió Francisco Ramírez Vas, médico y cirujano titular en Olivenza, quién vistos los casos que atendía en el Hospital de Caridad de esa localidad certificó que se trataba de cólera, por ello fue no solo insultado en público, además se le acusó de envenenador, porque supuestamente daba a los enfermos unos

un estudio del origen de la epidemia y de algunos errores de actuación ante ésta que se han cometido. Este documento solo lo podemos entender en el contexto de cambio político radical que supuso el triunfo de la Vicalvarada; Espartero asumió la presidencia del Gobierno el 19 de julio y tras un breve periodo de transición durante el que fue ministro de la Gobernación Antonio de los Ríos y Rosas, el 30 de julio ocupó la cartera Francisco Santa Cruz Pacheco, firmante de la R. Orden. El documento está tomado de Mariano GONZÁLEZ DE SAMANO: Memoria Histórica del..., vol. II, pp. 428-436.

30. Vicente PUYOL ARANGUREN: Examen comparativo de varios tratamientos empleados contra el cólera-morbo asiático, Pamplona, Imprenta de Longas y Ripa, 1855, p. 8.

31. Ángel APONTE MARÍN y Juan Antonio LÓPEZ CORDERO: "El miedo en Jaén. 3.2. La epidemia de cólera de 1854-1855", Jaén, Diputación Provincial, 2000, pp. 295. Recuperado de internet (https://www.pegalajar.org/miedo/miedo.htm). [consultado $16 / 12 / 2019]$

32. Junta Municipal de Valencia: Memoria sobre la invasión y curso del cólera morbo asiático en la ciudad de Valencia. Año 1854, Valencia, Imprenta de Jaime Martínez, 1855. 
polvos que los mataban y así él podía asegurar que había cólera, lo que le permitiría ganar una condecoración y 80 reales de vellón al día; el origen de sus problemas lo encontramos en el alcalde García Puente ${ }^{33}$

\section{La legislación y la movilidad}

Pese a esa negación inicial de que la enfermedad que había en Pontevedra fuese cólera, el gobierno reactivó la legislación previa para combatir la epidemia. El primer paso consistió en que el día 6 de enero, por medio de una circular, se recordó la legislación preexistente como por ejemplo las Reales Órdenes de 18 de enero de 1849 que regulaban diferentes asuntos en caso de que se decretase una epidemia de cólera y la Real Orden de 30 de marzo de 1849 relativa, como dice en su título, a las Instrucciones para Jefes Políticos y alcaldes sobre la adopción de disposiciones necesarias en caso de epidemia para contener o aminorar los efectos del cólera. Los Boletines oficiales de las provincias volvieron a publicar las Órdenes para conocimiento de todas las autoridades locales ${ }^{34}$

Por Real Orden de 18 de enero de 1849 se optó por evitar los confinamientos facilitando la movilidad interior y exterior; se argumentaba que en base a la experiencia adquirida durante la epidemia de cólera de 1834 las restricciones no solo no habían evitado la propagación de la enfermedad sino que además habían tenido funestas consecuencias para el abastecimiento de los pueblos; pero en realidad el Gobierno lo que hacía era proteger los intereses de la burguesía proteccionista, que se podía ver perjudicados si se tomaban medidas aislacionistas que entorpeciesen el comercio, sobre todo el interior ${ }^{35}$. No habría aislamiento de los enfermos ni en sus casas, ni en sus barrios, ni en los establecimientos sanitarios; tampoco se establecerían lazaretos ni cuarentas en las fronteras terrestres con Francia y Portugal en caso de que en esos países se declarase la epidemia; de hecho, cuando se vuelve a publicar esta R. Orden algunas zonas de Francia, como París, ya la estaban sufriendo. Se fiaba todo a la higiene "podrá evitarse [la extensión de la enfermedad] con el aseo y buen régimen" (sic). Esto explica la política de negación primero y ocultación después de la existencia de la epidemia, si los ciudadanos no eran conscientes de lo que estaba sucediendo ni criticarían la labor gubernamental ni le exigirían medidas más contundentes. No obstante, se tomaron algunas medidas, pero

33. José Luis SÁNCHEZ ÁlVAREZ y Diego PERAL PACHECO: "La epidemia de cólera de 1855 en Olivenza", Revista de Estudios Extremeños, tomo XLV, 3 (2009), pp. 1289-1320, esp. pp. 1299 y ss.

34. Por ejemplo, el Boletín Oficial de la Provincia de Segovia las publicó todas, 17 de febrero de 1854.

35. José Ramón URQUIJO Y GOITIA: "Madrid ante la epidemia de cólera de 1854-56", Asclepio, XXXV (1983), pp. 27-52, esp. p. 37. 
pocas y de poco calado, que disminuían la movilidad como por ejemplo mandar que los quintos de Galicia no salieran hacia otras provincias, formando 2 batallones que se disolverían en cuanto la situación mejorase incorporándose en esos momentos al resto del ejército ${ }^{36}$. Con la primavera avanzada se ordenó a los gobernadores civiles que diesen instrucciones a las autoridades locales para que, con el fin de evitar que la epidemia se expandiese, las cuadrillas de segadores se alojaran en habitaciones espaciosas y bien ventiladas, además de recomendar el aseo y el lavado de ropa ${ }^{37}$, nuevamente medidas de higiene pero sin prohibir el movimiento de las cuadrillas.

A nivel local, no obstante, de lo establecido en la normativa, desde el principio nos encontramos autoridades que restringieron la movilidad de bienes y personas. En algunas localidades se prohibió la entrada de gallegos ${ }^{38}$; en Madrid, el 1 de junio de 1854, el conde de la Oliva pidió en la sesión del Ayuntamiento que los numerosos gallegos que estaban en Madrid buscando trabajo y que dormían en los soportales de la Plaza Mayor fuesen obligados a dormir fuera de la ciudad ${ }^{39}$. Los Gobernadores Civiles de Coruña y Orense establecieron 3 lazaretos cada uno para que los ciudadanos procedentes de la provincia de Pontevedra tuviesen que pasar 3 días de cuarentena en observación ${ }^{40}$; la medida se complementó en La Coruña el 6 de mayo con una Circular del Gobernador Civil, Fernando Zappino, en la que además de prohibir la celebración de ferias en localidades que estuviesen a menos de 6 leguas de la provincia de Pontevedra, para evitar aglomeraciones que propiciaran la expansión de la epidemia, dejó un razonamiento sobre cuáles deben ser la razones que muevan a las autoridades a tomar las decisiones en coyunturas como la que estaban viviendo: “... y si bien esta medida podrá lastimar accidentalmente intereses particulares, estos deben posponerse al bien general de los pueblos, porque no hay nada más justo ni urgente que procurar por todos los medios la conservación de la salud pública" ${ }^{\prime 4}$.

Cuando la epidemia se extendió por todo el país las restricciones a la movilidad se multiplicaron; por ejemplo el 3 de agosto de 1854 el Ayuntamiento de Jerez, reunido con la Junta Municipal de Sanidad, acordó por unanimidad la incomunicación de la ciudad para evitar el contacto con las localidades contaminadas, Ilegando a tapiar varias calles para dejar únicamente 13 puertas y poder controlar las salidas y entradas; pese a las presiones del Gobernador de la provincia el ayuntamiento mantuvo el aislamiento; se estableció un lazareto en el Monasterio de La Cartuja, en donde debían pasar 10 días de cuarente-

36. El Porvenir Médico, 10 de febrero de 1854.

37. El Porvenir Médico, 5 de mayo de 1854.

38. El Genio de la Libertad, 3 de marzo de 1854.

39. José Ramón URQUIJO Y GOITIA: "Condiciones de vida y cólera...", p. 78.

40. El Siglo Médico, 7 de mayo de 1854.

41. La España, 18 de mayo de 1854. 
na las personas y mercancías; para todos aquellos que por motivos laborales tenían que salir de la ciudad se imprimió un salvoconducto que debía volver firmado por el dueño o capataz de la finca si se quería volver a entrar ${ }^{42}$, aunque con la llegada de la vendimia, actividad esencial para Jerez, los controles se relajaron ${ }^{43}$. El ayuntamiento de Gerona, debido a que la ciudad de Barcelona ya estaba afectada por el cólera reguló que los viajeros procedentes de allí, antes de entrar en la ciudad debían realizar una cuarentena en el barrio situado extramuros, bien en el lazareto habilitado en la Avellaneda o, quien pudiese permitírselo en alguna casa particular ${ }^{44}$. El Ayuntamiento de Alcañiz (Teruel), ante el temor de que la epidemia que ya afectaba a localidades cercanas Ilegase a la ciudad, acordó que desde el 15 de septiembre de 1854 se estableciesen guardias en las cuatro puertas, las del puente, San Francisco, Carmen y San Jaime; en las dos primeras de día y de noche, y en las dos últimas solamente desde las ocho de la mañana a las de la noche, cerrándose las puertas en el intermedio, siendo controladas por los vecinos ${ }^{45}$. En Jijona (Alicante) fueron los propios vecinos los que en agosto de 1854 forzaron a las autoridades locales a cerrar la localidad a las mercancías y personas procedentes de Alicante y las demás localidades en que se había declarado el cólera, que deberían hacer 8 días de cuarentena, cortando el importante camino real que comunicaba Valencia con Alicante ${ }^{46}$. En la provincia de Badajoz cuando comenzaron a circular rumores de una invasión colérica en Sevilla, muchas localidades de la provincia, especialmente las que se encontraban en la carretera de Andalucía decidieron aislarse impidiendo la entrada de viajeros, la Junta Provincial de Sanidad escribió un comunicado recordando las normas que prohibían el aislamiento, pero estableciendo, de forma contradictoria, un periodo de 3 días de cuarentena en 3 localidades (Monesterio, Fregenal y Llerena) para las personas procedentes de Sevilla, pasados los cuales si no manifestaban signos de estar enfermos la Junta Municipal de Sanidad les extendía un salvoconducto para circular libremente ${ }^{47}$; pocos días después el Gobernador civil tenía que publicar una circular reconociendo que el miedo estaba causando una exagerada interpretación de la nota

42. Diego CARO CANCELA: "El cólera-morbo en Jerez: la epidemia de 1854", Trocadero, 3 (1991), pp. 117-155. Recuperado de Internet (https://revistas.uca.es/index.php/trocadero/article/view/1039). [consultado 31/10/2020]

43. Ibid., p. 133.

44. José PORCALLA Y DIOMER: Historia del cólera-morbo epidémico que invadió la ciudad y partido de Gerona en el año 1854, Barcelona, Imprenta de Tomás Gorchs, 1859.

45. Archivo Municipal de Alcañiz (A.M.A.L.): Libro de Actas Municipales 1851-1855 (sig. 6979), acta de la sesión celebrada el 14 de septiembre de 1854. Recuperado de Internet (https://www.alcaniz.es/attachments/article/1845/200609_expoarchivoalcaniz_epidemias. pdf). [consultado 28/10/2020]

46. José BERNABÉ RUIZ: “La epidemia de cólera de 1854 en Xixona”, 2020. Recuperado de Internet (https://madeinjijona.com/la-epidemia-de-colera-de-1854-en-xixona/). [consultado $21 / 11 / 2020]$

47. Boletín Oficial de Badajoz, 94, 7 de agosto de 1854. 
anterior, impidiéndose en muchos lugares la entrada a cualquier viajero, aunque no procediese de Andalucía y amenazaba con multas de 50 duros a los que insistiesen en esas restricciones ${ }^{48}$. La amenaza no debió de ser muy disuasoria ya que el Gobernador Civil, ante el extendido incumplimiento por parte de los ayuntamientos de las normas que limitaban la movilidad, Ilegó a acusarlos de convertirse en "Corporaciones soberanas" 49 .

Como la legislación las prohibía no tenemos cifras oficiales, pero por las informaciones que de forma reiterada aparecen en la prensa debieron de ser muchas las localidades que establecieron medidas de aislamiento, tantas que el gobierno se vio en la necesidad de recordar en varias ocasiones que las autoridades debían facilitar la libre circulación de mercancías y pasajeros debiéndose además levantar los cordones sanitarios que se habían establecido en algunas poblaciones libres de cólera, primero con la R. Orden de 25 de agosto de $1854^{50}$ y al año siguiente cuando de nuevo la epidemia se recrudeció, con la R. Orden de 10 de agosto de 1855 titulada de forma explícita: "Real orden recordando la observancia de la del 25 de agosto último (1854) sobre la libertad en las comunicaciones" ${ }^{\prime 51}$; e inmediatamente después, el 22 de agosto de 1855, ante el pertinaz incumplimiento de las normas, una nueva R. Orden encargaba a los gobernadores que intentasen convencer a los municipios que se aislaban de que depusieran su comportamiento, en caso de que no lo hicieran primero deberían imponer multar y si se persistiese se llevase a los responsables ante los tribunales ${ }^{52}$.

\section{Las Juntas de Sanidad}

Otra Real Orden de 18 de enero completaba, para adaptarlo a las necesidades provocadas por la posible llegada del cólera, el Real Decreto de 17 de marzo de 1847, que había creado las Juntas de Sanidad; se sustituía la Junta Suprema de Sanidad por el Consejo de Sanidad del Reino con funciones consultivas (aa. 1 y 4), y se creaba en el Ministerio de la Gobernación una Dirección General Sanidad (a. 3). Se aumentaba el número de miembros de todas las juntas, ordenándose la creación de juntas municipales en aquellas localidades que por su escaso número de habitantes no las tuvieran constituidas en tiempo de normalidad sanitaria. Las funciones de la Juntas municipales las establecía el apartado $12^{\circ}$; debían resolver todos los problemas de salubridad 1854

48. Circular $n^{\circ}$ 182, 12 de agosto de 1854; Boletín Oficial de Badajoz, 97, 14 de agosto de

49. Circular 219; Boletín Oficial de Badajoz, 113, 22 de septiembre de 1854.

50. Tomada de Mariano GONZÁLEZ DE SAMANO: Memoria Histórica del..., vol. II., pp. 424-425.

51. Ibid., vol. II, pp. 446-447.

52. Ibid., vol. II, pp. 447-448. 
que hubiese en su localidad y "contener y minorar los estragos del cólera o cualquiera otra de mal carácter que reinase en la misma población o hubiese motivos fundados para temer su aparición en ella". En las Juntas municipales de las localidades con más de 20.000 habitantes, además de las provinciales y de partido que tuvieran carácter municipal, se crearía una Comisión permanente de salubridad pública, en el resto de las localidades se constituirían allí donde las características de la población lo permitiesen. Estas comisiones realizarían las tareas encargadas a las Juntas Municipales, trabajos que se concretaban en el apartado $15^{\circ}$, éstos consistían en el control de las aguas corrientes o estancadas, la vigilancia de la higiene de viviendas, de edificios en donde viviesen o se reunieran muchas personas (cuarteles, fábricas, teatros, hospicios...), el control de la venta de alimentos y bebidas, tener conocimiento sobre la atención sanitaria que se podía dar a los indigentes y una tarea en la que mezclaba la sanitario con lo moral: "Examinar por último, si entre los hábitos o costumbres de la generalidad de los habitantes, o de cualquiera de sus clases, hay algunos que puedan influir desventajosamente en la salud pública". Las Comisiones elaborarían un informe sobre todo lo referido al apartado 15 para presentárselo a las Juntas municipales. Los alcaldes debían enviar ese informe junto con los dictámenes de la Junta. La Junta provincial de Sanidad recibiría la documentación para elaborar un informe propio, que junto con un dictamen del Gobernador Civil serían remitidos al Gobierno. En las localidades de más de 10.000 habitantes los alcaldes debían dividir la localidad por barrios o parroquias, procurando coincidir con la división realizada por las juntas de beneficencia; el alcalde designaba a uno de los vocales de la Junta municipal de sanidad para vigilar cada una de estas zonas.

En 1853 Francisco Méndez Álvaro denunciaba que realmente solo se habían constituido unas pocas las Juntas, fundamentalmente en las localidades de mayor población, y que en muchas ocasiones los alcaldes, para no incumplir lo establecido en la normativa, se habían limitado a comunicar a los gobernadores civiles una serie de nombres, pero sin que realmente desempeñasen las funciones atribuidas ${ }^{53}$.

La Real Orden de 30 de marzo de 1849 completaba la legislación sanitaria. Se trata de una norma extensa que contiene 67 instrucciones, con una organización un poco caótica, sobre todo en la parte relativa a las recomendaciones higiénicas Por las cuestiones que regula y sobre todo por cómo las regula parece una norma pensada para un ámbito urbano o en todo caso de localidades con un tamaño medio, pero de imposible aplicación en el mundo rural; el enfoque urbano de la disposición es importante porque a mediados del siglo XIX la mayoría de la población española seguía viviendo en un ámbito rural y de

53. Francisco MÉNDEZ ÁLVARO: Consideraciones sobre la higiene pública y mejoras que reclama en España la higiene municipal, Madrid, Imprenta de José Rodríguez, 1853. 
facto quedaba excluida de muchos de los posibles beneficios que supusiese su aplicación.

Hay una clara intención de que, en caso de producirse, la epidemia pasase lo más desapercibida posible para la población, por ejemplo, se prohibía que las campanas de las iglesias tocasen a difuntos cuando hubiese un fallecimiento (Instr. 29), tampoco podrían ser expuestos los cadáveres ni en las iglesias ni en los cementerios (Instr. 35), los carruajes destinados al traslado de cadáveres debían ir siempre cubiertos y el traslado al cementerio se haría únicamente al amanecer o al anochecer, pero siempre sin pompa ni publicidad $(\operatorname{Instr} 33)^{54}$, como muchas de las disposiciones de esos momentos, ésta también fue incumplida por algunos curas párrocos ${ }^{55}$ y por otras autoridades. El 6 de octubre de 1855 el Gobernador Civil de Madrid, Luis Sagasti, mandó un oficio al Ayuntamiento de la capital recordando la prohibición de reuniones en los entierros, también los de los componentes de la Milicia Nacional, que no podían ser acompañados por miembros de sus compañías, incluidos los músicos. Además, se buscaba controlar la información ya que no se podrían publicar otros datos sobre enfermos o difuntos que los oficiales facilitados por las autoridades (Inst. 35). Hubo ayuntamientos que impusieron medidas más restrictivas, por ejemplo en Requena se estableció que los fallecidos debían trasladarse a partir de las 10 de la noche, por el camino más corto y menos visible ${ }^{56}$; en Olivenza (Badajoz) los difuntos debían llegar al carro que los llevaría al cementerio en "camilla cubierta" ${ }^{157}$

La primera parte de la R. Orden titulada: Precauciones higiénicas, comenzaba estableciendo que, dado que las competencias de sanidad eran del Ministerio de la Gobernación, se designaba a los Jefes políticos (Gobernadores Civiles) como máximos responsables de las cuestiones sanitarias en sus provincias y convirtiendo el desarrollo de la norma a los alcaldes en los responsables de la sanidad en sus municipios; esto se debe a que la función de las autoridades era básicamente la de ser una policía sanitaria ${ }^{58}$. El resto del capítulo consiste fundamentalmente, aunque no en exclusiva, en una serie de recomendaciones sobre cómo mejorar la higiene tanto individual como colectiva. Los consejos que da nos muestran el negativo de la fotografía de un país pobre y sucio. Todo se

54. Hay autores que consideran que esas medidas tenían un sentido diferente: una preocupación por la salud pública. Por ejemplo, Eduardo MARTíNEZ LACABE: "La epidemia de cólera de 1855 en Navarra: demografía y mentalidad", Revista Gerónimo de Uztariz, 12 (1996), pp. 89-114.

55. Ibid., p. 95.

56. Ignacio LATORRE ZACARÉS: “El cólera en Requena, una sociedad frente a la enfermedad", Cuadernos de Geografía, 95-96 (2014), pp. 201-225, esp. p. 216.

57. José Luis SÁNCHEZ ÁLVAREZ y Diego PERAL PACHECO: “La epidemia de cólera de 1855...", p. 1297.

58. José Javier VIÑES RUEDA: La sanidad española en la segunda mitad del siglo XIX, Navarra, Gobierno de Navarra, 2006, p. 73. 
basa en 3 principios: ventilación, limpieza y desinfección. La ventilación, dada la extendida creencia en el origen miasmático del cólera, se consideraba un aspecto fundamental de la prevención, se aconsejaba airear habitaciones, los establecimientos públicos y privados (iglesias, hospitales, escuelas, cuarteles, teatros...) en los que se reuniese mucha gente, además de los espacios como calles y plazas. La limpieza hacía especial hincapié en los focos de contaminación del agua (alcantarillas, pozos, letrinas, albañales, arroyos...) que hubiese en lugares habitados y en la vigilancia de las condiciones higiénicas de lugares cuyas actividades resultasen contaminantes tales como cebaderos de cerdos, mataderos, almacenes de pescado o fábricas de curtidos. Después vendría la desinfección de espacios privados y públicos, fundamentalmente con vapores o fumigaciones de cloro (Instrucciones 10 y 11). También se prohibía la venta de una serie de alimentos como pescado no fresco (salazones), carnes saladas, legumbres no maduras y embutidos. En la literatura médica de la época nos encontramos la teoría de que, dado que el cólera se manifiesta con síntomas gastrointestinales como vómitos y diarreas, ciertos alimentos, como la carne de cerdo, incluidos los embutidos, no causaban la enfermedad pero sí predisponían a que se sufriera ${ }^{59}$.

Pero qué sucede si después de ventilar, limpiar y desinfectar una fábrica, un almacén y lo más importante, una casa, siguen teniendo un ambiente no saludable. La instrucción $n^{\circ} 13$ no deja lugar a dudas, tras el pertinente informe de la Comisión Permanente de Salubridad y con refrendo de la Junta de Sanidad se cierran. Pero esta pretensión era en realidad un brindis al sol. ¿Cuántas viviendas había en malas higiénicas? Con toda seguridad muchísimas, el propio gobierno lo reconocía, en la citada R. Orden de 6 de septiembre de 1854 se decía: "En la mayor parte de los pueblos de alguna importancia y en Madrid, sobre todo, innumerables personas viven en boardillas, sotabancos, cuartos bajos, hasta en bodegones y sótanos inmundos ó mal sanos que son focos pestilenciales"; y muchas fuentes, especialmente médicas, lo corroboran, por ejemplo Francisco Méndez Álvaro, que era médico, hace una descripción similar de algunas zonas de Madrid; el doctor Pedro Felipe Monlau, en la memoria que presentó a la Academia de Medicina y Cirugía de Barcelona, decía: "Muchas son las habitaciones insalubres, pero las de la clase pobre, y por consiguiente las de los obreros, lo son todas" ${ }^{\prime 60}$; igual opinión tenía Juan Ceballos, catedrático de la Facultad de Medicina de Cádiz, respecto a su ciudad: "La mayor parte de las casas de vecindad se componen de cuartos pequeños, mal ventilados y reunión de individuos en mayor número del que deben contener" ${ }^{\prime \prime 1}$. La misma insalubridad sufrían las

59. Mariano GONZÁLEZ DE SAMANO: Memoria Histórica del..., vol. I, p. 88.

60. Pedro Felipe MONLAU: ¿Qué medidas puede dictar el gobierno a favor de las clases obreras?, Barcelona, Imprenta Politécnica de Tomás Gorchs, 1856.

61. Juan CEBALLOS: Consejos higiénico preservativos del cólera-morbo: discusión sobre su contagio, Cádiz, Imprenta de la Revista Médica, 1855. 
viviendas de las personas humildes en las zonas rurales; Francisco Méndez Álvaro las describe así: "Las clases pobres de nuestras provincias agrícolas suelen habitar chozas miserables, oscuras, sin ventilación, rodeadas por todas partes de establos, de cuadras, de estercoleros y de inmundicias" ${ }^{\prime \prime 2}$,

¿Qué harían las autoridades con los cientos y cientos de miles de viviendas que había en pésimas condiciones de salubridad? ¿Clausurarlas? En primer lugar, no se concreta qué criterios son los que determinan que una vivienda no es saludable y por lo tanto resulta imposible seguir viviendo en ella. Lo que es más importante: no resuelve qué hacer con las familias cuyas viviendas fuesen declaradas inhabitables, ¿en dónde pensaban alojarlas? ¿En grandes edificios como iglesias o cuarteles? ¿En las estancias no ocupadas de las mansiones de la aristocracia o de las amplias y confortables viviendas burguesas? ¿dejarlas en la calle?

La escasez de información al respecto parece indicar que en la mayor parte de las localidades no hubo posibilidad de llevar a cabo ninguna actuación; no obstante, en algunos sitios sí se intentó, aunque con poco éxito y mayoritariamente con unos tintes de discriminación social y aporofobia. En Valencia, al comenzar la epidemia en el verano de 1854, los primeros afectados fueron traslados a una casa de campo: la Huerta de San Pablo, situada a un cuarto de legua de la capital; tras diez días de estancia a expensas del Ayuntamiento regresaron a la ciudad ${ }^{63}$. La Junta Municipal de Sanidad de Jerez hizo la propuesta de que se habilitasen tiendas de campaña en el campo para alojar a pobres, aunque instaladas en un lugar que les permitiese todos los días volver a trabajar, lo que finalmente se llevó a cabo ${ }^{64}$; en Cádiz la sugerencia fue que en la periferia de la ciudad se construyesen para los pobres casas de vecindad nuevas ${ }^{65}$. En Madrid la propuesta de la Junta de Sanidad y Beneficencia fue que se estableciesen en los alrededores de la capital asilos provisionales de mendicidad, para trasladar a ellos a los vecinos más indigentes; finalmente solo se habilitó uno: el Cuartel de Leganés ${ }^{66}$, pero ese año no llegó a ocuparse; aunque el Ayuntamiento planteó la posibilidad de sacar a 5 ó 6 mil personas, de las más humildes de la ciudad, finalmente se desechó la idea por falta de fondos ${ }^{67}$; cuando en 1855 llegó una nueva ola epidémica sí se abrió el asilo de mendicidad de Leganés.

Que 5 años después de ser publicada por primera vez la Orden se pudiese repetir en los mismos términos nos indica que no había habido ningún interés

62. Francisco MÉNDEZ ÁlVARO: Consideraciones sobre la higiene ..., p. 45.

63. Junta Municipal de Valencia: Memoria sobre la invasión y..., pp. 93-94.

64. Diego CARO CANCELA: "El cólera-morbo en Jerez...", pp. 129 y 132.

65. Juan CEBALLOS: Consejos higiénico preservativos ..., p. 31.

66. S.a.: Memoria de las Juntas Municipales de Sanidad y Beneficencia de Madrid acerca de la epidemia de cólera-morbo padecida en esta capital en el otoño de 1854, Madrid, Oficina Tipográfica de la Junta Municipal de Beneficiencia, 1855.

67. José Ramón URQUIJO Y GOITIA: “Condiciones de vida y cólera...", p. 54. 
real en mejorar las condiciones higiénicas en las que vivían y trabajaban los españoles más pobres.

\section{La atención sanitaria}

La atención sanitaria de aquellos que no podían pagarse un médico estaba regulada por las Instrucciones 37 a la 61 de la citada R. Orden de 30 de marzo de 1849. La divide en 4 apartados: Hospitalidad domiciliaria, Casas de socorro, Hospitales comunes y Enfermerías del cólera. La autoridad sanitaria recaía en los políticos, jugando los alcaldes un papel fundamental, por ejemplo, era atribución suya, previo informe médico, decidir que enfermos son hospitalizados y cuáles no.

Como normativa nueva se publicó la Real Orden de 1 de febrero de 1854 que complementaba la de 30 de marzo de 1849 con la regulación de las visitas médicas domiciliarias preventivas realizadas por médicos diferentes a los del servicio de hospitalidad domiciliaria; estos médicos tenían el encargo de visitar las casas más pobres además de sus lugares de trabajo (talleres, fábricas, lavaderos...), vigilando no solo la salud, ya que debían tratar a los posibles enfermos de cólera, también debían comprobar la salubridad de las estancias; estos médicos debían dar diariamente parte por escrito sobre los pacientes tratados y los remedios prescritos al Inspector de distrito o parroquia. En cada localidad grande, aunque no se especifica que se entiende por localidad grande, pero debemos suponer que siguiendo lo establecido en una de las RROO de 18 de enero de 1849 son las mayores de 10.000 habitantes, los alcaldes nombrarían para cada parroquia un médico que hiciese de inspector controlando toda la atención médica (casas de socorro, hospitalidad domiciliaria y visitas preventivas) y elevando diariamente la información a los alcaldes; en las localidades pequeñas los médicos titulares eran los encargados de esas visitas domiciliarias preventivas y en caso de no haber médico titular el alcalde tendría que buscar quién las realice. La Orden se completaba con una serie de disposiciones sobre como reunir los datos médicos-administrativos que reflejan la incidencia y expansión la epidemia. En las localidades grandes se estableció como obligatoria la creación en el Ayuntamiento de un negociado de estadística del cólera para elaborar las estadísticas de la ciudad, que serían remitidas al Gobernador Civil.

Posteriormente se aprobó el Real Decreto de 5 de abril de $1854^{68}$, que en su exposición de motivos decía que el objetivo era convertir en norma la antigua costumbre de los pueblos de contratar médicos, en general para atender a los más pobres y en ocasiones para toda la población. El decreto regulaba y

68. Gazeta de Madrid, 12 de abril de 1854. 
generalizaba la atención sanitaria para los pobres, en su a. 1 decía "Todas las ciudades, villas y lugares del Reino, tendrán médicos, cirujanos y farmacéuticos titulares para la asistencia de los pobres, para el socorro de las demás personas que necesitaren de su auxilio, y para el desempeño de otros deberes que se expresan en el lugar correspondiente". ¿Quiénes estaban incluidos en la categoría de pobres? Los define el a. 5: "Primero. Aquellos vecinos que no contribuyen directamente con cantidad alguna al Erario ni son incluidos en los repartimientos para cubrir los gastos provinciales y municipales, ni reciben del Estado, de la provincia, del Ayuntamiento ó de un particular sueldo suficiente para cubrir las más precisas necesidades de la vida. Segundo. Todas las personas que componen las familias de dichos vecinos y los desvalidos que accidentalmente se hallaren en el pueblo ó transitaren por él"; los alcaldes tenían la obligación anual de hacer una lista con las personas de su municipio comprendidos en esa categoría. Las poblaciones de menos de 1500 vecinos podían elegir entre ser Partidos de Primera Clase, es decir tener facultativos solo para los pobres, o ser Partidos de Segunda Clase encargándoles también la asistencia del resto del vecindario (aa. 3 y 4); las localidades de más de 1.500 vecinos eran Partidos de Primera clase, la asistencia sería solo para los pobres. En los Partidos de primera el resto de los vecinos podían voluntariamente establecer igualas para ser atendidos; la responsabilidad de fijar los Partidos era, oídos los ayuntamientos, del Gobernador Civil, que lo harían atendiendo fundamentalmente a criterios numéricos, tendrían un médico titular las que contasen aproximadamente con un mínimo de 200 vecinos, cirujano las que tuviesen 100 vecinos y farmacéuticos las de 1.000, aunque si podían pagar la retribución mínima exigida podían constituirse partidos sanitarios con menos vecinos; cuando una localidad contase con menos de 200 vecinos podía agregarse a otra cercana para formar Partido sanitario; las de más de 1500 vecinos se dividían en Partidos, que no podían superar los 3.000 vecinos.

Las retribuciones, que podían ser monetarias o en especie, las establecerían los ayuntamientos, aunque nunca podrían ser inferiores a 2.000 reales anuales para los médicos y 800 para los cirujanos, fijados para los partidos de 200 vecinos; estas retribuciones se incrementaban en proporción al número de vecinos atendidos (por cada 20 vecinos más aumentaba en 100 reales para los médicos y 50 para los cirujanos); los farmacéuticos cobraban 20 reales anuales por cada vecino incluido en la lista de pobres y en los Partidos de Segunda clase 26 por los no incluidos, viudas y huérfanos pagaban la mitad. Los ayuntamientos eran los encargados de pagar las retribuciones de los sanitarios (a. 36), teniendo libertad para decidir el origen de los fondos, que podían proceder en su totalidad o en parte de productos de los bienes de propios, de repartimientos entre los vecinos con una derrama o de arbitrios facilitados por los gobernadores civiles (a. 37). Los vecinos de los Partidos de Primera de menos de 1500 vecinos que no estuviesen en la lista de pobres podían acordar igualas con el titular o con cualquier otro facultativo; en los de más de 1500 vecinos la libertad de contratación 
de servicios sanitarios era total; en ambos casos lo único que hace el Decreto es fijar unos precios mínimos. Este decreto tenía otra consecuencia no señalada en su preámbulo, se aseguraba a los profesionales sanitarios una retribución mínima que no quedaba al criterio de la cicatería o la generosidad de las autoridades locales y los vecinos. Aunque supuso un incremento en las retribuciones de los sanitarios; por ejemplo en los presupuestos del Ayuntamiento de Requena para 1854 se establecían unos salarios inferiores ya que los facultativos que asistían a los pobres recibirían 1.000 reales el médico, 600 el cirujano y 800 el farmacéutico ${ }^{69}$. Pese a esta mejora no estaban especialmente bien pagados, un obrero cualificado, como los cajistas de imprenta, podía ganar unos 4.000 reales al año, el doble que un albañil picapedrero ${ }^{70}$.

La Real Orden de 21 de agosto de 1854 del Ministerio de la Gobernación nos muestra la dificultad de cumplir, con los medios de que se disponía, lo establecido en la R. Orden de 30 de marzo de 1849 al reiterar que las autoridades debían ejecutar las medidas establecidas en ella, con el doble objetivo de evitar que llegase la epidemia y disminuir sus efectos, en caso de lo hiciese.

En plena epidemia, el 28 de noviembre de 1855, se aprobó una ley sanitaria: la Ley de Sanidad. El texto inició su lentísimo, más teniendo en consideración la situación sanitaria, trámite parlamentario el 29 de marzo con su presentación por parte del Ministro de la Gobernación, el todavía progresista, Francisco Santa Cruz Pacheco; en su exposición de motivos daba dos claves de las necesidades de la organización sanitaria en España: la falta de una norma general, ya que la legislación era una suma de disposiciones variadas, y la necesidad de armonizar nuestra ley con lo establecido en otros países dado el incremento del comercio internacional ${ }^{71}$. El texto introdujo pocas novedades importantes respecto a la organización sanitaria y la lucha contra las epidemias; se establecían las cuarentenas para los barcos con patente sucia de peste levantina, fiebre amarilla y cólera morbo-asiático. Pese a la evidencia de que los desplazamientos de grupos de numerosas personas, como el ejército de O'Donnell o las reuniones de quintos en las capitales provinciales, favorecía la extensión de la epidemia se mantuvo la prohibición de cuarentenas interiores (a. 57), siendo potestad exclusiva del Gobierno establecer medidas restrictivas de los movimientos de personas si circunstancias especiales lo demandaban (a. 58), por lo tanto ninguna otra autoridad como Gobernadores Civiles o alcaldes podían atribuirse tal potestad, tal como había sucedido los 2 años anteriores. Se reducía el número de Juntas Municipales de Sanidad al fijar en 1000 el número de habitantes necesarios para que una localidad tuviese que constituirla (a. 52); la máxima autoridad de la Junta Municipal

69. Ignacio LATORRE ZACARÉS: “El cólera en Requena...", p. 214.

70. José Ramón URQUIJO Y GOITIA: "Condiciones de vida y cólera...", p. 102.

71. Lourdes FARRERONS NOGUERA: Historia del sistema sanitario español: Debates parlamentarios, 1812-1986, Madrid, Ed. Díaz de Santos, 2013. 
seguía recayendo en el alcalde, que ejercía de presidente, pero se daba relevancia a los sanitarios ya que se componía de un médico, un farmacéutico, un veterinario, un cirujano (en caso de que lo hubiese) y 3 vecinos (a. 54), aunque la concreción de sus funciones quedaba pendiente de un reglamento posterior (a. 55). La atención sanitaria a los pobres sería responsabilidad de los Ayuntamientos, que debían crear plazas de médicos, cirujanos y farmacéuticos titulares para cumplir esa función, además de sufragar sus retribuciones, pero las cantidades a recibir por los médicos no se fijaban; cabía la posibilidad de que varios Ayuntamientos, por escasez de población o de recursos mancomunasen la atención sanitaria (aa. 64 al 67). Para intentar evitar el problema de las huidas de algunos profesionales sanitarios durante una epidemia, como estaba sucediendo desde 1854, se prohibía que los facultativos titulares abandonar la localidad en que ejerciesen su profesión si había una epidemia (a. 72), en caso de hacerlo serían privados de su derecho a ejercer la profesión durante un tiempo que decidiría el Gobierno de acuerdo con las causas atenuantes y agravantes que concurriesen en cada caso (a. 73). Dos asuntos provocaron malestar entre los profesionales sanitarios, mantenía una prohibición, acompañada de la correspondiente penalización, que consideraban discriminatoria; además, al no fijar retribuciones mínimas, como sí había hecho el R. Decreto de 4 de abril de 1854, sus salarios quedaban a criterio de los ayuntamientos ${ }^{72}$. Una cuestión clave es en qué medida la nueva Ley de Sanidad tuvo influencia en la atención sanitaria durante la epidemia de cólera de 1853-56; si la tuvo debió de ser mínima, primero por la fecha de aprobación casi a finales del año 55 y segundo por los acontecimientos políticos. Tras la renuncia de Espartero y el nombramiento del general O'Donnell como Presidente del Consejo de Ministros en julio de 1856 la Ley de Sanidad quedó en el limbo, hasta el punto de que en febrero de 1859 el parlamentario González de la Vega preguntó si la ley de Sanidad estaba en vigor, la respuesta que recibió no dejó lugar a dudas: el Gobierno no tenía interés en ella y por lo tanto no se cumplía ${ }^{73}$.

\section{La lucha contra los efectos de la epidemia}

La legislación daba a las Juntas de Sanidad, especialmente a las municipales, un papel clave en la lucha contra la epidemia, no sólo en la misión fundamental de recaudación de fondos.

Ejercieron el papel de policía sanitaria controlando la venta de alimentos que se consideraban podían ser propiciatorios de la enfermedad como el pescado o la carne ${ }^{74}$, pero sobre todo la fruta, llegándose en casos extremos, como en

72. Mariano GONZÁLEZ DE SAMANO: Memoria Histórica del cólera..., vol. II, pp. 53-54.

73. Lourdes FARRERONS NOGUERA: Historia del sistema sanitario español..., p. 74.

74. Magdalena VALENZUELA GUZMÁN: "1855. Epidemia de cólera en Huelma...", p. 242; Diego CARO CANCELA: "El cólera-morbo en Jerez...", p. 124. 
Requena, a prohibir la venta de frutas del 13 de julio al 22 de agosto de $1855^{75}$. Aunque a veces los intereses económicos se imponían sobre los sanitarios, así el Ayuntamiento de Jerez rechazó la propuesta de la Junta Municipal de Sanidad de impedir la venta de frutas de temporada como uvas, melones y sandías, con el argumento de que causaría la ruina de los numerosos vecinos que vivían de su producción o venta ${ }^{76}$.

En muchos lugares realizaron actuaciones para controlar las condiciones higiénico-sanitarias, tanto de espacios públicos como privados. Se cursaron visitas domiciliarias para ver de las condiciones higiénicas de viviendas, patios y zonas comunes en diversas localidades, por ejemplo en Logroño ${ }^{77}$, en Cádiz ${ }^{78}$ o en Huelma (Jaén), en donde se limpiaron con el método de fumigación las viviendas de los afectados ${ }^{79}$, igual se hizo en Chinchón (Madrid) ${ }^{80}$. De manera recurrente se dictaron instrucciones prohibiendo la convivencia con animales, especialmente cerdos, aunque a veces también gallinas como en la localidad jienense de Pegalajar ${ }^{81}$ o en Manresa (Barcelona) ${ }^{82}$. Se retiraron animales muertos de las calles. Vigilaban que no se produjesen estancamientos de aguas; se controlaron los lavaderos públicos, por ejemplo en Huelma se estableció que las ropas de los fallecidos habían de lavarse pasadas 24 del óbito y además debía de hacerse en el Barranco de la Ermita para abajo ${ }^{83}$. En Jerez se cerraron las casas de párvulos ${ }^{84}$. En Olivenza, por indicación de los médicos de la localidad, como medida profiláctica se suspendió en julio de 1855 la lactancia de los niños de la casa de misericordia ${ }^{85}$.

75. Ignacio LATORRE ZACARÉS: “El cólera en Requena...", p. 218.

76. Diego CARO CANCELA: "El cólera-morbo en Jerez...", p. 131.

77. Salvador SAENZ CENZANO: "Apuntes históricos de Logroño: la epidemia de cólera de 1854", Revista Berceo, 8 (1948), pp. 287-420.

78. Juan CEBALLOS: Consejos higiénico preservativos ..., p. 32.

79. Magdalena VALENZUELA GUZMÁN: "1855. Epidemia de cólera en Huelma...", pp. 239-242.

80. Raúl PANADERO GARCÍA: "Epidemias de cólera en Chinchón durante el siglo XIX". En Concurso de investigación sobre Chinchón y su entorno, 2007, pp. 201-255. Recuperado de Internet (https://studylib.es/doc/7519520/epidemias-del-c\%C3\%B3lera-en-chinch\%C3\%B3nen-el-siglo-xix). [consultado 22/11/2019]

81. Juan Antonio LIETOR MORALES, José ROJAS LÓPEZ y José LÓPEZ CORDERO: Pegalajar: nueva aproximación histórica, Pegalar (Jaén), Ayuntamiento de Pegalajar, 1994. Recuperado de Internet (https://www.pegalajar.org/nuevaaproximacionhistorica/capitulo_iv_3_5b. htm). [consultado 03/05/2020]

82. Base documental d'Història Contemporània de Catalunya.Regnat d' Isabel II (18331868) - Bienni Progressista (1854-1856). Recuperado de Internet (http://www.xtec.cat/ jrovira6/ isabel21/colera3.htm). [consultado 12/07/2020]

83. Magdalena VALENZUELA GUZMÁN: "1855. Epidemia de cólera en Huelma...", p. 242.

84. Diego CARO CANCELA: "El cólera-morbo en Jerez...", p. 131.

85. José Luis SÁNCHEZ ÁLVAREZ y Diego PERAL PACHECO: "La epidemia de cólera de $1855 \ldots . .$, p. 1297. 
De forma generalizada las Juntas facilitaron la distribución de publicaciones informativas métodos y remedios contra la enfermedad.

También era competencia de las Juntas la habilitación de Casas de Socorro y de hospitales de coléricos. En Logroño se instalaron en la planta baja de 2 edificios: el instituto y el seminario ${ }^{86}$, en Gerona lo hicieron en la subida de Santa Lucía, en el barrio de San Pedro, zona pobre de la ciudad y la más afectada ${ }^{87}$. No siempre fue una tarea fácil la instalación de un hospital de coléricos; en ocasiones provocaba protestas de los vecinos; en Badajoz el Capitán General habilitó uno en el Convento de San Agustín, pero las quejas vecinales le obligaron a trasladarlo a la Alcazaba del Castillo ${ }^{88}$; otras veces la dificultad estribaba en encontrar disponibles los edificios adecuados, en 1854 la Junta Municipal de Madrid sufrió el contratiempo de que los propietarios de las casas desocupadas que podían albergar los hospitales se negaban a alquilárselas ${ }^{89}$, finalmente el único hospital de coléricos que se abrió en la capital ese año estuvo localizado en el claustro del Monasterio de san Jerónimo, cedido por la reina. Muchos de estos hospitales se instalaron en edificios antiguos, a veces incluso ruinosos, que carecían de las condiciones higiénicas necesarias para atender a los enfermos ${ }^{90}$.

Una tarea fundamental de las Juntas fue paliar, en la medida de sus posibilidades, las necesidades de los más pobres. Se encargaron de buscar médicos y farmacéuticos que los atendiesen y les dieran gratis los medicamentos. Hubo localidades en las que facilitaron alimentos e incluso pequeñas cantidades de dinero a los necesitados, de algunos sitios, como Huelma, la información es imprecisa: se entregó a los pobres jamón, carne y azúcar, además de algo de dinero ${ }^{91}$; pero de otros lugares es mucho más concreta; en Jerez desde el 25 de septiembre de 1854 se repartieron a los pobres 400 raciones diarias, incrementadas hasta 700 desde el 4 de octubre al disponer de más dinero, compuestas de un cazo de caldo con garbanzos, una onza de tocino, cuatro de carne y un cuarterón y medio de pan ${ }^{92}$; en Requena, durante el brote de 1855, la ayuda que recibieron las familias pobres fue de una libra de carne y 6 reales para matrimonios con cuatro de familia en adelante; 12 onzas de carne y 5 reales para el matrimonio con tres de familia y media libra de carne y 4 reales para el matrimonio con hasta dos de familia ${ }^{93}$.

86. Salvador SAENZ CENZANO: "Apuntes históricos de Logroño...", p. 347.

87. José PORCALLA Y DIOMER: Historia del cólera-morbo epidémico..., p. 10.

88. Pilar RODRÍGUEZ FLORES: Epidemia y sociedad en Badajoz (1854-1866), Badajoz, Diputación Provincial de Badajoz, 1996, p. 102. Recuperado de Internet (http://www.cervantesvirtual.com/nd/ark:/59851/bmc891t9). [consultado 28/10/2020]

89. S.a.: Memoria de las Juntas Municipales...de 1854, pp. 11-12.

90. Mariano GONZÁLEZ DE SAMANO: Memoria Histórica del cólera..., vol. II, p. 129. 242.

91. Magdalena VALENZUELA GUZMÁN: "1855. Epidemia de cólera en Huelma...", p.

92. Diego CARO CANCELA: "El cólera-morbo en Jerez...", p. 141.

93. Ignacio LATORRE ZACARÉS: "El cólera en Requena...", p. 221. 
Singular fue la decisión que tomó el Ayuntamiento de Jerez para intentar controlar la posible especulación propiciada por el aislamiento de la ciudad; el 13 de agosto de 1854 se publicó un bando prohibiendo la subida de los precios de los artículos de primera necesidad ${ }^{94}$. En septiembre, con el mismo objetivo, recibieron del Gobernador Civil la autorización para fijar tablas de precios para la venta de carne y cecina, poniendo además panaderías bajo su control ${ }^{95}$.

\section{7. ¿Moral o ciencia?}

En una intencionada y confusa mezcla entre moral y ciencia, las relaciones sexuales eran catalogadas de forma reiterada por médicos como un factor que predisponía al padecimiento de la enfermedad; por ejemplo Mariano González Samano, tras estudiar los afectados por cólera por grupos de edad, y pese a aceptar que no había pruebas concluyentes que avalasen su teoría, Ilega a la conclusión de que: "está más apto a contraer la enfermedad, aquel en el cual por razones naturales y leyes tanto divinas como humanas, están en continuada aptitud y poco interrumpida acción, sus órganos sexuales" ${ }^{\prime \prime 6}$. En ese frecuente interés por inculcar valores morales bajo un supuesto pretexto sanitario también cayó la Real Academia de Medicina de Madrid, que en unas instrucciones para prevenir el cólera además de reiterar los consejos higiénicos y alimenticios ya mencionados, decía: "...si todos los escesos suelen pagarse muy caros mientras reina una epidemia, pocos habrá tan funestos como los que se cometen contra la castidad. La incontinencia ha hecho muchas víctimas aún en tiempos normales; pero durante el cólera, tal vez no haya cosa que más predisponga a contraer la enfermedad. Húyase pues de todo abuso en esta parte ${ }^{\prime \prime 97}$. De haber sido cierta la teoría, la reina Isabel II habría sido una de las personas con mayor probabilidad de contraer el cólera.

Estas ideas también impregnaban las disposiciones legales. Aparte de las recomendaciones higiénico-sanitarias, en la R. Orden de 30 de marzo de 1849 se incluyen otras de índole moral para combatir la posible propagación del cólera. Entre los malos hábitos que en opinión del autor de la norma facilitan la extensión de la enfermedad se cita la incontinencia (debemos de entender que sexual) y los excesos en la comida y la bebida. Tales postulados se basaban, en teoría, en algunos criterios médicos que defendían que, además de ciertos alimentos, las bebidas alcohólicas (vino y licores) alteraban estómago e intestinos, favoreciendo la propensión entre los bebedores

94. Diego CARO CANCELA: "El cólera-morbo en Jerez...", p. 141.

95. Ibid., p. 139.

96. Mariano GONZÁLEZ DE SAMANO: Memoria Histórica del..., vol. I, pp. 91-93.

97. S.a.: Las instrucciones populares para la prevención del cólera morbo y curación de sus primeros síntomas, Madrid, Real Academia de Medicina de Madrid, 1854. 
a sufrir la enfermedad; pero en realidad era cuestión estrictamente moral y además poco realista ${ }^{98}$, seguramente uno de los riesgos más pequeños que había a mediados del siglo XIX era que los pobres enfermasen por un empacho de comida.

En el mismo sentido moralista, aunque con repercusiones políticas, hay que incluir el encargo a las autoridades de que dirigieran consuelos y exhortaciones para que los estragos de la plaga se asumiesen con resignación (Instrucción 21); si la población aceptaba como algo inevitable la epidemia no sentiría la tentación de exigir responsabilidades.

También encontramos una visión moralizante en el a. 26 del Real Decreto de 5 de abril de $1854^{99}$, que entre las obligaciones de los cirujanos fijaba la de registrar todos los nacimientos de su circunscripción, reflejando día, y hora, sexo y nombre de los padres "cuando de esto no haya inconveniente".

\section{La huida}

Miedo, mucho miedo, es lo que producía el cólera entre la gente. El temor a la enfermedad provocó de forma reiterada, sobre todo por parte de los grupos sociales más pudientes, un comportamiento: la huida de las ciudades que se veían afectadas por la epidemia. Así describía un contemporáneo lo sucedido en Barcelona: "Únicamente permanecían en Barcelona aquellas familias que tenían algún individuo atacado de cólera, los boticarios herboristas, médicos y demás personas cuyas obligaciones les impedían abandonar la ciudad y aqueIlos infelices que por falta de recursos no podían seguir en la huída a sus conciudadanos afortunados. Es decir, que en Barcelona no quedaron otros pobladores que aquellos obligados por el deber o la miseria"100. Los pobres huyeron en menor número, pero no fue por valentía, sino por no carecer de recursos económicos para vivir fuera de su vivienda habitual un tiempo indeterminado, que podía ser largo.

Los ejemplos son numerosos. En Badajoz capital el cólera comenzó el 12 de septiembre del 54, de inmediato la abandonaron las clases acomodadas, entre otros el alcalde, varios regidores, 2 médicos y un farmacéutico; la Junta Municipal de Sanidad calculó que se marcharon de la ciudad unas 2000 personas $^{101}$. En el

98. Mariano GONZÁLEZ DE SAMANO defiende esa teoría, pero al mismo tiempo reconoce que hay "bebedores de vino" que no fueron atacados por el cólera Memoria Histórica del..., vol. I, pp. 89-90.

99. Gazeta de Madrid, 12 de abril de 1854.

100. Conrad ROURE: Recuerdos de mi larga vida, Barcelona, s.e., 1925, vol. I, pp. 33-38. Recuperado de Internet (http://www.xtec.cat/ jrovira6/isabel21/colera54.htm). [consultado $17 / 11 / 2019]$

101. José Luis SÁNCHEZ ÁLVAREZ y Diego PERAL PACHECO: “La epidemia de cólera de 1855...", p. 1294. 
verano de 1854 Barcelona, como ya se dicho, sufrió una verdadera desbandada, los que salieron de la ciudad se marcharon hacia la montaña y las provincias limítrofes como Gerona ${ }^{102}$ expandiendo la enfermedad. Cuando llegó el cólera a la ciudad de Gerona se repitió la situación y muchos de los que por sus recursos se lo podían permitir abandonaron la ciudad ${ }^{103}$; también tenemos noticias de vecinos de Jaén que salieron hacia Cazorla y Jódar (extendiendo la enfermedad) ${ }^{104}$; de Huelma (Jaén) al Ilegar la epidemia en junio de 1855 huyeron los más adinerados $^{105}$; y de Alicante, que partieron hacia Denia, Alcoy y Villena ${ }^{106}$. El 4 de diciembre de 1855 la Gazeta calculaba en más de 35.000 los retornados a Madrid desde finalizado el brote de ese año, días después elevaba la cantidad a $43.000^{107}$; esta cifra aunque fuese exagerada, igual que la descripción barcelonesa, nos hablan de una realidad innegable: hubo huidas masivas.

Un agravante de la huida de las élites sociales y económicas fue cuando la llevaban a cabo personas que tenían responsabilidades esenciales en la lucha contra la epidemia como las autoridades municipales, los funcionarios y lo más sorprendente: los médicos. El problema, como se puede deducir de las disposiciones legales que intentan atajarlo, ya se había producido en la epidemia colérica de la década de los 30. Por orden cronológico, una R. Orden de 4 de julio de 1834 inhabilitaba para el ejercicio de la medicina a los médicos que abandonasen su localidad en tiempos de epidemia ${ }^{108}$, otra R. Orden de 30 de julio del 34 del Ministerio de Hacienda sancionaba con la pérdida de 6 meses de salario a sus empleados que abandonasen su localidad por estar contaminada ${ }^{109}$ y la R. Orden de 1 de agosto de 1834, que tras informar de que se habían recibido noticias de que algunos alcaldes y autoridades locales habían abandonado su municipio ante la llegada de la enfermedad, ordenaba a los Gobernadores Civiles que multasen esos comportamientos ${ }^{110}$. Pero como podemos deducir de las R. Órdenes que emitió el Ministerio de la Gobernación, los comportamientos se repitieron en la epidemia comenzada en 1853; la R. Orden de 25 de agosto de 1854 prohibía a autoridades y funcionarios abandonar sus localidades huyendo de la enfermedad, en caso de hacerlo se entendería como una renuncia a su cargo, además de estar sujetos a las posibles penas establecida en la ley; por ejemplo un regidor del Ayuntamiento de Montijo (Badajoz) fue multado

102. Mariano GONZÁLEZ DE SAMANO: Memoria Histórica del cólera..., vol. I, p. 290.

103. José PORCALLA Y DIOMER: Historia del cólera-morbo epidémico..., p. 29.

104. Mariano GONZÁLEZ DE SAMANO: Memoria Histórica del cólera..., vol. I, p. 304.

105. Magdalena VALENZUELA GUZMÁN: "1855. Epidemia de cólera en Huelma...", p. 241.

106. Mariano GONZÁLEZ DE SAMANO: Memoria Histórica del cólera..., vol. I, p. 296.

107. José Ramón URQUIJO Y GOITIA: "Condiciones de vida y cólera...", pp. 121-122.

108. Tomada Mariano GONZÁLEZ DE SAMANO: Memoria Histórica del cólera..., vol. II, pp. 299-300.

109. Ibid., vol. II, p. 303.

110. Ibid., vol. II, pp. 303-304. 
con 200 reales de vellón por haber abandonado su localidad ${ }^{111}$. La R. Orden de 1 de septiembre hace referencia a que los médicos no pueden abandonar sus localidades por la llegada del cólera, pudiendo ser sancionados por tal acción. La R. Orden de 6 de septiembre también se refiere al mismo problema, además incluye a los escribanos y los curas párrocos entre los que huyen de las localidades contaminadas. El caso de Jerez nos muestra como fue la situación; una vez declarada la epidemia a principios de septiembre, huyó de la ciudad las mayor parte de los miembros del consistorio, incluido el alcalde, Juan Sixto Oronoz, cuando el Gobernador de la provincia convocó a los 150 mayores contribuyentes de la ciudad para constituir un nuevo ayuntamiento solo se presentaron 2 de ellos a la primera reunión y 4 a la segunda, las clases más adineradas de Jerez habían huido ${ }^{112}$. De Alicante en agosto de 1854 salieron huyendo las clases altas, las autoridades, los sacerdotes e incluso los médicos ${ }^{113}$.

Es evidente que el miedo a la enfermedad era mayor que el temor que producían las posibles repercusiones legales de la huida. Cuando en abril de 1855 se produjo la segunda oleada epidémica en la ciudad de Jaén, una parte de sus concejales abandonó la ciudad ${ }^{114}$; lo mismo sucedió en localidad de Pegalajar (Jaén) unos meses más tarde, cuando en julio la enfermedad causaba una mortalidad más alta huyeron la mayor parte de los concejales ${ }^{115}$. A veces las autoridades huían incluso antes de que llegase la enfermedad, como sucedió en Cartagena, de donde se marcharon el alcalde, la mayoría de los concejales e incluso miembros de las Juntas de Sanidad ${ }^{116}$. En el mismo año de 1855 huyeron los médicos de varias localidades navarras: Berbinzana, Valle de Yerri, Maya de Baztan, Cortes de Navarra, Artajona, Cirauqui,... ${ }^{117}$. En 1855, en la pacense Torrehermosa la epidemia fue tan fuerte que el miedo hizo huir a toda la población dejando solos a los enfermos, en Usagre (Badajoz) solo quedó el párroco y en Azuaga (Badajoz) huyeron todas las autoridades.

Esta reiteración en los comportamientos de abandono de funciones por parte de las personas responsables provocó que al año siguiente el gobierno considerara necesario repetir las prohibiciones. La R. Orden de 19 de julio prohibía a los médicos que fuesen titulares de la localidad o cobrasen de alguna institución pública (municipal, provincial o estatal) abandonar la localidad en la que ejerciesen en caso de epidemia, en caso de hacerlo perderían sus salarios además

111. Ma del Pilar RODRÍGUEZ FLORES: Epidemia y sociedad en Badajoz..., p. 151.

112. Diego CARO CANCELA: "El cólera-morbo en Jerez...",pp. 135-138.

113. José BERNABÉ RUIZ: "La epidemia de cólera de 1854 en Xixona".

114. Ángel APONTE MARÍN y Juan Antonio LÓPEZ CORDERO: "El miedo en Jaén...".

115. Juan Antonio LIETOR MORALES, José ROJAS LÓPEZ y José LÓPEZ CORDERO: Pegalajar: nueva aproximación...

116. Recuperado de Internet (https://www.regmurcia.com/servlet/s.SI?sit=c,373\&r=ReP23568-DETALLE_REPORTAJESABUELO). [consultado 14/01/2020]

117. Eduardo MARTíNEZ LACABE: “La epidemia de cólera de 1855 en Navarra...", p. 103. 
de sufrir las sanciones previstas en los códigos para los funcionarios que abandonasen sus destinos sin permiso ${ }^{118}$. En el mismo sentido iba la R. Orden de 29 de julio del Ministerio de Gracia y Justicia prohibiendo que sus funcionarios abandonasen una provincia en caso de que estuviera invadida por el cólera ${ }^{119}$. Por último, la ley de Sanidad de 1855, aprobada en noviembre, se ocupaba del problema prohibiendo a los facultativos titulares (médicos, cirujanos y farmacéuticos) abandonar las localidades en que ejercían en el supuesto de que se declarase una epidemia, sancionándolos con la inhabilitación temporal en caso de incumplimiento.

A veces eran las autoridades eclesiásticas las que se marchaban en cuanto tenían ocasión, por ejemplo Cipriano Juárez Berzosa, obispo de Calahorra y La Calzada, abandonó la ciudad de Logroño el 23 de noviembre de 1854, cuando estaba en lo más álgido de la epidemia, después de haber ofrecido en una pastoral sus auxilios a los afectados, el resto de los sacerdotes de Logroño se mantuvieron en sus puestos, falleciendo algunos por cólera ${ }^{120}$. Ese comportamiento había sido la causa del Real Decreto de Ministerio de Gracia y Justicia de 30 de agosto de 1854, que ante los abandonos por parte de algunos religiosos de las localidades, infectadas establecía que las autoridades eclesiásticas recodasen al clero sus obligaciones, remitiesen al Ministerio el listado de los incumplidores e impusiesen sanciones dentro del ámbito de competencias eclesiásticas ${ }^{121}$.

El miedo a que fueran portadores de la enfermedad provocó que en ocasiones los huidos de las ciudades ya contagiadas no fuesen bienvenidos. De la ciudad de Sevilla salieron en agosto de 1854 muchas familias, que no fueron bien acogidas en las localidades en las que pensaban refugiarse, llegando a ser recibidas con pedradas y tiros en algunas como Osuna y El Arahal ${ }^{122}$. Las autoridades eran conscientes de este problema, Ramón Cuervo, Gobernador Civil de Badajoz en septiembre de 1854 denunciaba que en algunos lugares se había rechazado a viajeros con "rusticidad salvaje" y se les había obligado a pernoctar a la intemperie, una situación parecida sufrieron los huidos de Logroño en noviembre de 1854, fueron rechazados en las localidades vecinas, teniendo que refugiarse en corrales o incluso quedarse a la intemperie ${ }^{123}$.

118. Tomada de Mariano GONZÁLEZ DE SAMANO: Memoria Histórica del cólera..., vol. II, pp. 444-445.

119. Ibid., vol. II, pp. 445-446.

120. Juan Carlos BILBAO DíEZ: "La epidemia de cólera de 1855 en la ciudad de Logroño", Cuadernos de Investigación: Historia, tomo 10, 1 (1984), pp. 113-124, esp. p. 121.

121. Gaceta de Madrid, 607, 31 de agosto de 1854.

122. El Siglo Médico, 20 de agosto de 1854, p. 267.

123. Salvador SAENZ CENZANO: "Apuntes históricos de Logroño...", pp. 348-349. La misma información encontramos en Juan Carlos BILBAO DíEZ: "La epidemia de cólera de 1855 ...", p. 121. 
Es comprensible que los que se quedaron en sus localidades, voluntaria o forzosamente, no tuvieran buena opinión de los que las habían abandonado. En Requena en 1854 se acordó la exposición pública de los nombres de los huidos ${ }^{124}$, un pequeño escarnio público, también se prohibió la vuelta de los huidos hasta de después de cuarenta días de haber cantado el Te Deum; además de la venganza, el objetivo fundamental debió de ser profiláctico: evitar que la epidemia volviese a la localidad ${ }^{125}$. La misma prohibición encontramos en Badajoz, que además de a los forasteros prohibió la entrada en la ciudad a los huidos, para evitar un rebrote del cólera ${ }^{126}$. La de Requena no fue la única exposición pública del nombre de los huidos, por ejemplo en Badajoz se hizo público el listado de personas con responsabilidades públicas que habían huido de Almedralejo, una relación inicial incluía, entre otros, a 10 religiosos, 2 procuradores y 2 médicos cirujanos titulares ${ }^{127}$, posteriormente se completó con la relación de autoridades municipales que habían abandonado la localidad, empezando por su alcalde Felipe Vargas, seguido de 2 tenientes de alcalde y 9 regidores, uno de ellos, Manuel Pérez, era médico ${ }^{128}$.

Pero también hubo casos de responsabilidad absoluta en el cumplimiento de sus obligaciones, por ejemplo en el brote de 1855 en la localidad de Requena de los 8 facultativos que había, 5 murieron de cólera y otros 2 enfermaron, quedando solo un médico en activo, que pese a ser un enfermo crónico continuó atendiendo sus obligaciones ${ }^{129}$. En la localidad de Bienvenida (Badajoz) fue encomiable la actuación de su alcalde, que aseguró el reparto diario a los pobres de raciones de pan, carne, tocino y garbanzos y la de José $\mathrm{M}^{\mathrm{a}}$ de Castillo, médico y cirujano, que atendió a centenares de enfermos ${ }^{130}$. El alcalde de los Arcos (Navarra), aunque un tercio de los vecinos huyeron al llegar la enfermedad, se mantuvo en su puesto y junto con Nicolás María Arbizu, vecino adinerado de la villa, ayudó a sus convecinos en todas sus necesidades ${ }^{131}$

Una consecuencia de la huida de la burguesía fue la pérdida de puestos de trabajo, ya que se cerraban talleres y negocios, lo que acentuaba las penalidades de los más humildes. Hubo autoridades, como José García de Leonardo, $2^{\circ}$ teniente de alcalde de Requena, que para combatir el paro y las consiguientes pobreza y hambre propusieron como solución la realización de obras públicas como caminos ${ }^{132}$; en algunos lugares esto se llevó a cabo; Pascual Madoz,

124. Ignacio LATORRE ZACARÉS: "El cólera en Requena ..." p. 223.

125. Ibid., p. 216.

126. Pilar RODRÍGUEZ FLORES: Epidemia y sociedad en Badajoz..., p. 57.

127. Ibid. p. 154.

128. Boletín Oficial de Badajoz, 129, 30 de octubre de 1854.

129. Ignacio LATORRE ZACARÉS: "El cólera en Requena...", p. 214.

130. Boletín Oficial de Badajoz, 131, 31 de octubre de 1855.

131. Eduardo MARTíNEZ LACABE: "La epidemia de cólera de 1855...", p. 101.

132. Ignacio LATORRE ZACARÉS: "El cólera en Requena ...", p. 205. 
Gobernador de la provincia de Barcelona, encargó la demolición de la muralla para dar trabajo a muchos de los que se habían quedado sin empleo ${ }^{133}$. Francisco Latasa, alcalde de Logroño, publicó el 23 de noviembre de 1854 un bando ofreciendo 5 reales diarios, la mitad a los niños, a todos los jornaleros que trabajasen en el tajo abierto en el camino de Logroño a Villamediana; el salario era tan alto que llegaron a presentarse 400 trabajadores, algunos incluso después de abandonar sus talleres para incorporarse a la obra. De inmediato se rebajó el salario y se exigió que se presentasen con alguna herramienta para el trabajo, lo que disminuyó el número de empleados ${ }^{134}$. En 1856, ante la situación de pobreza causada por los efectos de la epidemia el Gobernador Civil de Badajoz, solicitó al Gobierno que le autorizase contratar 1500 jornaleros, a distribuir proporcionalmente entre los partidos judiciales de la provincia según su población, para trabajar en la construcción de la carretera de Badajoz a Sevilla ${ }^{135}$.

\section{Lo que una epidemia cuesta}

La legislación establecía qué había que atender las necesidades residenciales, alimenticias y laborales de los más pobres, además de las sanitarias. Pero ¿con qué recursos económicos se contaba para afrontar esta tarea? La Instrucción $n^{\circ} 18$ de la citada R. Orden nos lo aclara: "se hará en cuanto sea posible" y "siempre que la población lo permita". Tal inconcreción no es casual, es la puerta abierta para que lo recogido en la norma quede simplemente en una mera declaración teórica de intenciones. Podríamos pensar lo contrario si además de dar a las autoridades locales instrucciones sobre qué hacer en esas situaciones, el Gobierno hubiese establecido un mecanismo para dotarlas de recursos económicos extraordinarios procedentes de sus presupuestos. El 28 de junio de 1853 la Junta General de Beneficencia solicitó al Ministerio de la Gobernación que incluyese en el presupuesto de 1854 una partida extraordinaria en beneficencia de un millón de reales para hacer frente a las posibles calamidades públicas, pero el Ministerio hizo caso omiso. Ya con la epidemia desatada una Real Orden de 9 de junio permitió al Ministerio de Gobernación, para atender el "socorro de calamidades públicas", el traspaso de 560.000 reales procedentes de un crédito extraordinario del presupuesto de 1853 destinados a atender la situación de miseria que habían vivido en Galicia y Asturias y que no habían sido gastados. En septiembre de 1854 el gobierno, en la citada R. Orden de 6 de ese mes, reconocía que no se había hecho nada de lo previsto, ni en sanidad ni beneficencia, debido a la escasez de recursos económicos. Desde ese momento se habilitaron una serie de partidas extraordinarias para el Minis-

133. Conrad ROURE: Recuerdos de mi..., vol. I, pp. 33-38.

134. Salvador SAENZ CENZANO: "Apuntes históricos de Logroño ...", pp. 350-351.

135. Boletín Oficial de Badajoz, 140, 24 de noviembre de 1854, pp. 1-2. 
terio de Gobernación, el Real Decreto de 18 de octubre le concedió un crédito suplementario de 558.00 reales $^{136}$; en el presupuesto de 1855 se le incluyó un crédito de 2.000.000 de reales "para calamidades públicas, objeto desatendido en anteriores presupuestos"137.

No sabemos cuánto se gastó el gobierno en atender estas necesidades sanitarias extraordinarias generadas por la epidemia. Según La Gazeta de Madrid ${ }^{138}$ el gasto total asumido por el presupuesto estatal fue de 13.489.162,06 reales, que sirvieron para atender únicamente a 261.615 enfermos por cólera de los 829.189 afectados que oficialmente se reconocen. Para valorar la cuantía de lo aportado por el gobierno lo podemos comparar con el presupuesto de la Casa Real para el año 1855, que ascendía a 33.000.000 reales ${ }^{139}$. Los gastos producidos debieron ser mucho mayores, Francisco Méndez Álvaro los calculó en unos 40 millones de reales, habiéndose cubierto la diferencia con fondos procedentes de las instituciones provinciales y sobre todo las municipales; que en muchísimas ocasiones, dado lo establecido en la normativa, tuvieron que recurrir a la caridad de la ciudadanía ${ }^{140}$. Una parte de lo aportado por los ciudadanos fue a fondo perdido, pero otra parte, en cambio, era reembolsable ${ }^{141}$. Un artículo muy posterior de EI Siglo Médico titulado "Lo que una epidemia cuesta" elevaba la cifra de los costes de la epidemia a 63.489.162 reales; además de los 13.489.162 reales sumaba 20 millones en indemnizaciones a los facultativos que se tuvieron que jubilar y a los familiares de los fallecidos y otros 30 millones por los daños que provocó la paralización de la industria y el comercio ${ }^{142}$; para que el cálculo fuese completo habría que añadir los 26 millones y medio en que había valorado Méndez Álvaro las aportaciones de los Ayuntamientos y Diputaciones Provinciales.

Dada la enorme debilidad financiera del Gobierno la carga económica extra que suponía hacer frente a la epidemia recayó la principalmente en las autoridades provinciales, sobre todo las municipales. Una Real Orden de 9 de noviembre de 1848 recogía la recomendación de que pueblos y provincias incluyeran en sus presupuestos "una cantidad suficiente" para atender las necesidades que

136. Boletín Oficial del Ministerio de Hacienda, tomo X, n 252, 26 de octubre 1854, p. 323.

137. Real Decreto autorizando al ministro de Hacienda para que someta a la deliberación de las Cortes los presupuestos generales para el año 1855 (17/XII/1854). Boletín Oficial del Ministerio de Hacienda, tomo X, n 261, 18 de diciembre de 1854, p. 472.

138. La Gazeta de Madrid, 12 de diciembre de 1857, p. 3.

139. Real Decreto autorizando al ministro de Hacienda para que someta a la deliberación de las Cortes los presupuestos generales para el año 1855 (17/XII/1854). Boletín Oficial del Ministerio de Hacienda, tomo X, no 261, 18 de diciembre de 1854, p. 476.

140. El Siglo Médico, 11 de octubre 1857.

141. Real Decreto de 17 de mayo de 1856. Tomado de Mariano GONZÁLEZ DE SAMANO: Memoria Histórica del..., vol. II, pp. 457-459.

142. El Siglo Médico, 8 de octubre de 1865. 
se provocaran en caso de que el cólera llegase a España. La R. Orden de 27 de junio de 1849 convertía en obligatorio lo que en la R.O. anterior había sido una indicación, ya que como recoge en su preámbulo en muchos lugares no se incluía esa partida o se hacía con unas cantidades claramente insuficientes ${ }^{143}$.

Para obtener fondos con que cubrir esos posibles incrementos en los gastos, la R. Orden de 6 de septiembre de 1854 establecía una serie de mecanismos que permitían a los ayuntamientos obtener recursos extraordinarios, por un lado podían disponer de la quinta parte de los pósitos, allí donde todavía los hubiese, también podían fijar gravámenes sobre artículos de primera necesidad y hacer derramas vecinales aplicando lo establecido en los artículos 33 y siguientes de la Ley para el gobierno económico-político de las provincias de 2 de febrero de 1823, que por Real Decreto de 7 de agosto de 1854 había sido puesta en vigor.

Pero si con esos recursos no había suficiente para afrontar los pagos, la Instrucción $n^{\circ} 41$ ya había explicado de dónde podrían salir parte de los fondos extraordinarios necesarios para hacer frente a todas las necesidades sociales y médicas: "adoptarán los Jefes Políticos y Alcaldes cuantos medios les sugiera su celo para excitar la filantropía de la clases acomodadas"; es decir: se tendría que recurrir a la caridad, aceptándose además de dinero, todos aquellos enseres: ropa de cama, colchones,..., que pudiesen utilizarse en las atenciones hospitalaria y domiciliaria. Una R. Orden de 21 agosto de 1854, además de recordar a las autoridades la necesidad de cumplir con sus obligaciones de beneficencia, reiteraba a las Juntas de beneficencia que hiciesen Ilamamientos a la "caridad pública y privada" (sic) para atender las necesidades de los enfermos indigentes ${ }^{144}$.

Algunos ayuntamientos se anticiparon a las necesidades que podrían surgir en caso de que la epidemia llegase, por ejemplo el de Requena (Valencia) el 9 de febrero, 7 meses antes de padecer el cólera, aprobó un presupuesto extraordinario de 20.000 reales de vellón para atender la lucha contra la enfermedad $^{145}$. El 3 de septiembre de 1854, el Ayuntamiento de Montijo (Badajoz), cuando todavía no había sufrido la invasión, aunque sí la padecía la vecina localidad de Puebla de la Calzada, acordó solicitar al Gobernador Civil que le permitiese utilizar el trigo del pósito para cubrir los gastos que provocara la atención a los más pobres en caso de que la enfermedad llegara ${ }^{146}$; ese año de 1854 la localidad se libró, pero cuando llegó en 1855 el ayuntamiento no disponía de fondos, por lo que para hacer frente a los gastos: 4.000 reales por

143. Tomada de Mariano GONZÁLEZ DE SAMANO: Memoria Histórica del ..., vol. II, pp. 399-400.

144. Ibid., pp. 423-424.

145. Ignacio LATORRE ZACARÉS: "El cólera en Requena...", p. 204.

146. Paloma GONZÁLEZ CASTILLO; María Luz GÓMEZ GARCíA y V. GONZÁLEZ GALÁN: "La salud pública en las actas municipales de Montijo: 1832-1855", Revista de Estudios Extremeños, tomo LIX, 1 (2003), pp. 145-160. 
el salario de 2 médicos auxiliares que ayudaron a los titulares y otros 641 reales para pagar los gastos de farmacia por los medicamentos suministrados a los pobres por los 2 farmacéuticos, tuvo que recurrir a préstamos y al sobrante de la subasta y remate de los arbitrios de pesos y medidas ${ }^{147}$. El Ayuntamiento de Alcañiz (Teruel), en sesión plenaria de 1 de septiembre de 1854, acordó un presupuesto extraordinario de 28.000 reales para atender las posibles necesidades en caso de que la localidad se viese afectada ${ }^{148}$.

Pero no todos los Ayuntamientos fueron tan previsores, o quizás carecían de recursos para poder serlo ya que la situación de sus arcas no se lo permitía, por ejemplo el alcalde de Alconera (Badajoz) reconocía que cuando el 18 de octubre de 1855 el cólera llegó a su pueblo, afectando de inmediato a 12 personas, carecía completamente de recursos para atender a los enfermos por lo que tuvo que solicitar un donativo entre sus vecinos consiguiendo recaudar 428 reales $^{149}$

En la práctica cada localidad tuvo que hacer frente a los gastos extraordinarios como buenamente pudo, utilizando las posibilidades que les daba la legislación. Era previsible, pero no por eso menos destacable, el hecho de que la fuente de ingresos más común, y en no pocos lugares la más cuantiosa, fuera la caridad de los propios vecinos. En ocasiones las autoridades reconocían que ante la falta de fondos estatales el único recurso disponible era la solidaridad de los ciudadanos, es lo que hizo Ramón Cuervo, Gobernador Civil y presidente de la Junta Provincial de Sanidad de Badajoz, en un bando de 12 de septiembre de 1854 que decía: "Pero como estas útiles disposiciones requieran gastos de consideración que no pueden ser atendidos con fondos del Estado, es preciso que la caridad cristiana del vecindario, proporcione los recursos indispensables a tan filantrópico objeto"150. En ocasiones la caridad tomó forma de prestación de servicios, como en Valencia durante la ola de 1854; las Hijas de la Caridad colaboraron en la atención de los enfermos ingresados en los hospitales de coléricos $^{151}$ y la Asociación de Nuestra Señora de los Desamparados repartió alimentos entre los más pobres, Ilegando a proporcionar hasta 11.000 raciones al día para una población de unas 100.000 personas ${ }^{152}$.

Más frecuente fue la donación de dinero. En Gerona la mayor parte de los vecinos participaron en una suscripción popular para hacer frente a los gastos

147. Ibid., p. 158.

148. Archivo Municipal de Alcañiz (A.M.A.L.): Libro de Actas Municipales 1851-1855 (sig. 6979), acta de la sesión celebrada el 1 de septiembre de 1854. Recuperado de Internet (https:// www.alcaniz.es/attachments/article/1845/200609_expoarchivoalcaniz_epidemias.pdf). [consultado 05/12/2019]

149. Boletín Oficial de Badajoz, 130, 29 de octubre de 1855.

150. Pilar RODRÍGUEZ FLORES: Epidemia y sociedad en Badajoz...

151. Junta Municipal de Valencia: Memoria sobre la invasión y..., p. 37.

152. Ibid., p. 89. 
que ocasionaba la epidemia ${ }^{153}$. En la sevillana localidad de Alcalá del Río, ante los primeros casos de cólera diagnosticados, la Junta Municipal de Sanidad decidió la habilitación de un hospital para coléricos; todos los fondos necesarios fueron aportados por los propios vecinos ${ }^{154}$. La Junta Parroquial de Beneficencia del distrito de San Francisco, de la ciudad de Santander, en su detalladísima memoria de actuaciones durante la epidemia, consigna que recaudó un total de 47.284 reales y 16 maravedís, de los que solo 3.000 reales, menos de un $7 \%$, fueron aportados por el Ayuntamiento de la ciudad, el resto se recogió gracias a las aportaciones de particulares, en cantidades que oscilaban entre los 2.286 reales y 26 maravedís que donó Antonio Gallo y los 4 reales con que contribuyó Manuel Madrazo; además hay que reflejar los 3.000 reales que donó la Corona por medio del obispo y los 2.500 del propio obispo de la ciudad ${ }^{155}$. En Málaga durante 1854 una suscripción pública consiguió una enorme cantidad de dinero, en diciembre se llevaban recaudados 353.000 reales, con algunas aportaciones significativas de miembros de la alta burguesía local (los hermanos Larios y Manuel A. Heredia aportaron 25.000 reales o Jorge Loring 20.000) ${ }^{156}$.

Lo más habitual era que los ayuntamientos recurriesen a varias fuentes de financiación. Madrid es un ejemplo; igual que todo el país la capital sufrió una falta crónica de recursos estatales y tuvo que emprender una búsqueda, a veces desesperada, de dinero para poder hacer frente al cólera. En septiembre de 1854, ante el comienzo de la epidemia en la ciudad, la Junta Municipal de Sanidad y Beneficencia acordó llevar a cabo una serie de actuaciones: abrir casas de socorro (una por parroquia) y hospitales de coléricos, además de un plan de visitas médicas preventivas; pero hacían falta unos recursos económicos, que el Estado inicialmente no aportó y el Ayuntamiento tampoco podía proporcionar. Las consecuencias fueron inmediatas, el plan de visitas preventivas a domicilio, previsto en Real Orden de 1 de febrero de 1854 y que había funcionado positivamente en otros países, y cuyos resultados en Madrid la propia Junta calificaba de lisonjeros (sic) tuvo que ser abandonado a los 10 diez días de su inicio por falta de dinero ${ }^{157}$ e incluso se llegaron a producir plantes del personal sanitario porque no se les abonaban los salarios que demandaban ${ }^{158}$. Ante la escasez de dinero, en ese año solo un organismo público: la Diputación Provincial, hizo una aportación, 100.000 reales; la Junta

153. José PORCALLA Y DIOMER: Historia del cólera-morbo epidémico..., p. 11.

154. Anales de Homeopatía (Madrid), Tomo III, 1854, p. 379.

155. S.a.: Memoria que la Junta Parroquial de Beneficencia del distrito de San Francisco publica para dar cuenta de su administración en el tiempo que el cólera morbo asiático afligió a los habitantes de esta capital, Santander, Imprenta y Litografía de Martínez, 1855.

156. José Antonio JIMÉNEZ QUINTERO: "La epidemia de 1854-1855", Revista Jábega, 16 (1976), pp. 29-34. Recuperado de Internet (https://www.cedma.es/catalogo/jabega. php?numero=16). [consultado 17/04/2020]

157. S.a.: "Memoria de las Juntas Municipales... de 1854", pp. 15-17.

158. José Ramón URQUIJO Y GOITIA: "Condiciones de vida y cólera...", p. 94. 
acordó, en su reunión del 24 de septiembre, hacer un llamamiento, que tuvo poco éxito, para que las personas acomodadas de la capital hiciesen donaciones que permitieran la apertura de las Casas de socorro. Pocos días más tarde, el 29 de septiembre, fue el Ayuntamiento quién planteó la misma medida: pedir ayudas a personas pudientes afines al sistema político para atender las necesidades de los más pobres y así evitar la posible conflictividad social. Se elaboró una lista de 80 nombres a los que solicitar una aportación económica, bien como donativo, bien como anticipo sin intereses; finalmente solo 46 de los registrados en la lista hicieron aportaciones ${ }^{159}$. Otras muchas personas sí hicieron donaciones, aunque la memoria de la Junta no recoge si las cantidades se dieron a fondo perdido o si eran total o parcialmente reintegrables; las cuantías fueron muy diversas, desde los humildes 2 reales de Juan del Peral o los 8 de Gregorio Cuevas hasta los 6.000 del Duque de Osuna, los 10.000 del empresario y político de origen navarro Nazario Carriquiri o los 12.000 de la Reina. Durante el año 1854 la Junta de Sanidad contó con unos recursos que sumaron 302.489 reales y 16 maravedíes, más del $60 \%$ procedente de donaciones particulares. La cantidad fue insuficiente para cubrir los 366.950 reales y 29 maravedíes a que ascendió el total de gastos producidos; esto supuso que al acabar el año la Junta debía, por falta de fondos, 65.296 reales y 12 maravedíes $^{160}$. Al año siguiente el Ayuntamiento habilitó una partida de 60.000 reales para cubrir la deuda pendiente.

En marzo de 1855 la epidemia volvió a campar por la capital y de nuevo hubo que hacer frente a numerosos gastos: hospitales de coléricos, Casas de socorro, asistencia hospitalaria domiciliaria, asilo de pobres de Leganés... Otra vez se vivió una situación de precariedad por falta de fondos; por ejemplo las Juntas parroquiales en vez de nombrar inspectores que ejecutasen las medidas de higiene tuvieron que designar para esta tarea a miembros de las propias Juntas, ya que carecían de dinero para pagar el salario establecido en las instrucciones $^{161}$.

Ante la falta de fondos la Junta de Sanidad y Beneficencia planteó 2 posibilidades para obtenerlos: que el Ayuntamiento solicitase autorización para hacer una derrama de 2 ó 3 millones de reales entre toda la población o recurrir a un empréstito de 500.000 reales, 1/3 de los cuales debía ser entregado de inmediato; los capitalistas plantearon que para asumir el préstamo necesitaban garantías fuertes y rápidamente recuperables; las ideas no cuajaron. El 3 de mayo el Ayuntamiento celebró una sesión extraordinaria dedicada al cólera; para solucionar el problema de la financiación propusieron o hacer una sus-

159. Ibid., pp. 93-95.

160. S.a.: Memoria de las Juntas Municipales... de 1854, pp. 40-41.

161. S.a.: Memoria de las Juntas Municipales de Sanidad y Beneficencia de Madrid acerca de la epidemia de cólera-morbo padecida en esta capital en el otoño de 1855, Madrid, Oficina Tipográfica de la Junta Municipal de Beneficiencia, 1856, p. 137. 
cripción entre todo el vecindario o hipotecar alguna finca de propios ${ }^{162}$. Posteriormente, ante la ineficacia de los llamamientos públicos, el Ayuntamiento se planteó otras alternativas: hacer una visita a domicilios de los más pudientes, incluida la Reina, para pedirles aportaciones; dar una o dos funciones de toros; solicitar al Gobierno poder disponer de una finca de propios y pedir al Ministro de Hacienda el adelanto de alguna cantidad. El 20 de julio, ante el incremento de los casos de cólera y la falta de dinero, el Gobierno acordó que se entregase a la Junta Municipal de Salud y Beneficencia de Madrid el sobrante del fondo especial de impresiones ${ }^{163}$. En ese año, según los datos de la Junta de Sanidad y Beneficencia, los ingresos alcanzaron la cuantía de 359.862 reales y 12 maravedíes; aunque la procedencia del dinero fue muy diferente a la de 1854. El Ayuntamiento aportó 281.801 reales y 3 maravedíes; la Diputación Provincial dio 30.000 reales, la Reina donó otros 20.000 reales; las donaciones privadas, que habían sido la principal fuente de recursos el año anterior, quedaron reducidas a 13.222 reales y 7 maravedíes, más de 9.000 de los cuales procedían de una función de teatro organizada por el periodista y político Ángel Fernández de los Ríos. Finalmente el Estado dio 200.000 reales al Ayuntamiento para cubrir parte de los gastos ya pagados ${ }^{164}$.

Los gastos también presentan algunas diferencias, mientras que en 1854 la mayor cuantía se dedicó a las obras necesarias para la habilitación de los edificios además de la compra de mobiliario y material para poner en funcionamiento los hospitales de coléricos, en total más de 200.000 reales; la segunda partida en importancia fue el pago de salarios, más de 100.000 reales; 54.000 de los cuales quedaron pendientes de pago ${ }^{165}$. En 1855 el total de los gastos asumidos por la Junta ascendió a 341.277 reales y 13 maravedíes, siendo la partida más importante y con diferencia, el abono de las retribuciones del personal sanitario $^{166}$.

En Chinchón durante 1855, según los datos presentados al Ayuntamiento por Jacinto García, depositario de los fondos de beneficencia, la epidemia había supuesto unos gastos de 18.986 reales y se habían recaudado 18.958 reales; 13.235 en un repartimiento entre los vecinos y la mayor parte de resto por donaciones; en julio de 1856 la Diputación entregó al Ayuntamiento 8.463 reales, por los gastos que tuvo por la epidemia ${ }^{167}$.

Para poder disponer de recursos para hacer frente a los gastos el Ayuntamiento de Jerez recibió autorización de Ríos Rosas, Gobernador Civil, para utilizar los fondos en metálico, los créditos realizables y negociables, el grano del pósi-

\footnotetext{
162. José Ramón URQUIJO Y GOITIA: "Condiciones de vida y cólera...", pp. 97-99.

163. Ibid., p. 102.

164. S.a.: Memoria de las Juntas Municipales... de 1855, p. 135.

165. S.a.: Memoria de las Juntas Municipales... de 1854, p. 41.

166. S.a.: Memoria de las Juntas Municipales... de 1855, pp. 133-134.

167. Raúl PANADERO GARCÍA: "Epidemias de cólera en Chinchón...", p 239.
} 
to, y para hipotecar bienes de Propios ${ }^{168}$. En esta ciudad se recaudaron 669.321 reales y 23 maravedíes, la mayor parte, 468.348 reales y 21 maravedíes, procedentes de la Caja de la Obra Pía del Pósito, la caridad también supuso un aporte importante: 91.557 rs y 22 maravedíes en dinero a lo que hubo que sumar bienes por valor de 7020 reales (entre las aportaciones hubo algunas cuantiosas procedentes de la alta burguesía jerezana como los 6.000 rvn de Rafael Rivero o los 5000 que aportaron Patricio Garvey y Juan Pedro Domecq) ${ }^{169}$; además la colaboración ciudadana supuso el aporte de otros 99.571 reales y 6 maravedís en suscripción reintegrable, el total se completa 3134 reales y 8 maravedís de ingresos especiales. El gasto de mayor cuantía fue la asistencia médica con 158.865 reales; todo lo relacionado con el enterramiento de las víctimas se elevó a 100.902 reales, la Juntas Parroquiales para atender sus necesidades recibieron 61.316 reales; otros gastos de menor cuantía como alimentos, gastos de limpieza, gastos de los hospitales suponen el resto de las inversiones ${ }^{170}$.

En Monforte del Cid (Alicante) gracias a la caridad vecinal se recaudaron 1353 reales de vellón, debiendo completarse los recursos necesarios con fondos de Propios y del depositario del Pósito ${ }^{171}$.

El Ayuntamiento de Badajoz propuso que se hiciese frente a los gastos causados en 1854 con el $20 \%$ de las rentas de Propios y con un recargo en algunos productos de consumo y en junio de 1855 que en caso de invasión colérica se incrementasen en un $2 \%$ las contribuciones territorial e industrial, además solicitó 6000 duros (120.000 reales) de lo aprobado en las Cortes para calamidades públicas $^{172}$.

Las Diputaciones Provinciales también dispusieron de fondos para atender las necesidades causadas por el cólera, pero la cantidad era pequeña en comparación con lo recaudado por los ayuntamientos y sobre todo con la cuantía de los gastos a cubrir, por ejemplo la Diputación de Valencia contaba con unos escasísimos 100.000 reales $^{173}$.

\section{Contagiados y fallecidos}

Las consecuencias más dramáticas de cualquier epidemia son las demográficas. El Gobierno por medio de La Gazeta de Madrid del 12 de diciembre de 1857 publicó las cifras oficiales; según esos datos en la epidemia de cólera que

168. Diego CARO CANCELA: "El cólera-morbo en Jerez...", p. 139.

169. Ibid., p. 142.

170. Ibid., pp. 150-151.

171. Recuperado de Internet (https://www.monfortedelcid.info/actualidad/colera-epidemia-monforte-del-cid-1854/) [consultado 01/03/2020]

172. Pilar RODRÍGUEZ FLORES: Epidemia y sociedad en Badajoz..., p. 72.

173. Ignacio LATORRE ZACARÉS: “El cólera en Requena ...", p. 221. 
sufrió España de 1853 a 1856 hubo 829.189 personas contagiadas, de las que fallecieron 236.744.

Pero con toda certeza se puede afirmar que la cifra real fue superior. Ya en la época los datos fueron cuestionados por incompletos, no sólo por artículos de la prensa especializada como El Siglo Médico, en dónde se pudo leer lo siguiente: "Personas invadidas y muertas hubo muchas más, sobre todo de las primeras; por cuanto el Gobierno carece de medios para averiguar todas las que los facultativos asisten, y las que sufren el mal sin asistencia facultativa sucediendo a menudo que los facultativos no califican bien la enfermedad en los certificados de defunción. Podrán elevarse a un millón (en números redondos) los invadidos y a 300.000 los muertos"174; también algunas Juntas de Sanidad dudaban de su fiabilidad, por ejemplo la de Madrid en su memoria del año 1855 dice que los datos que ofrece son inferiores a los reales; los de afectados porque no se habían recibido todos los partes sanitarios y porque los médicos no incluían en ellos los casos que consideraban leves. Calculaba en 4.210 los fallecidos reales ese año frente a los 3.762 reconocidos oficialmente porque en algunas certificaciones de defunción eran registrados como muertos por otras enfermedades ${ }^{175}$.

La dificultad para conocer las cifras reales es la misma en las grandes ciudades que en localidades mucho más pequeñas. En Madrid según los datos oficiales durante los 3 años de la epidemia hubo 4.455 fallecidos, pero en realidad pudieron ser más de 7.000 ${ }^{176}$. En Requena (Valencia) durante la oleada de 1855 las cifras oficiales reconocen 610 muertes, pero muy probablemente la cifra real de defunciones fuese $635^{177}$.

Aunque no es posible dar un número global cierto de víctimas mortales de la epidemia, sí se pueden encontrar las razones que propiciaron la infravaloración de las cifras. Se produjeron casos ocultamiento por parte de autoridades que no reconocían la enfermedad en su localidad, como el de Zafra o el de aldeas cercanas a Olivenza, como la de San Jorge, en las que los médicos atendieron a enfermos de cólera pero no consta ninguna defunción por esa causa ${ }^{178}$. Hay también noticias de retrasos por parte de las autoridades en reconocer la llega-

174. El Siglo Médico, 8 de octubre de 1865.

175. S.a.: Memoria de las Juntas Municipales... de 1855, pp. 10-11. Calcula en 9.463 la media de defunciones anuales en el trienio 1852/54 y compara la cifra con las 13.673 que hubo en 1855.

176. José Ramón URQUIJO Y GOITIA: "Condiciones de vida y cólera ...", pp. 125-127. EI autor compara los datos de cada mes en que hubo epidemia durante el trienio 1854/56 con la media del mes durante el periodo 1850/1853, llegando a la conclusión de que hay que incrementar el número total de defunciones en un $65 \%$.

177. Ignacio LATORRE ZACARÉS: “El cólera en Requena...", pp. 204-205. Tras revisar los datos del Registro Civil, el autor concluye que hubo 25 fallecimientos más de los recogidos en la estadística oficial.

178. José Luis SÁNCHEZ ÁlVAREZ y Diego PERAL PACHECO: “La epidemia de cólera de $1855 \ldots$..., p. 1308. 
da de la enfermedad, a veces varios días, lo que propiciaba que los primeros fallecidos no fuesen contados como coléricos. En los hospitales de Badajoz durante 1854 no se utilizó la palabra cólera como causa de fallecimiento hasta el 15 de septiembre, empleándose durante los días anteriores términos como diarrea, cólico bilioso o cólico fulminante ${ }^{179}$. Incluso hubo Juntas de Sanidad, como el caso ya citado de Valencia, que justificaban el retraso por considerarlo beneficioso.

En ocasiones la finalización real de la epidemia era posterior a la oficial, no contabilizándose en la estadística oficial esas últimas defunciones. En Olivenza (Badajoz) en el año 1855 el cólera finalizó oficialmente el 2 de septiembre con 97 fallecidos reconocidos, pero en los archivos parroquiales siguieron registrándose fallecimientos por cólera hasta alcanzar la cifra de 119 defunciones ${ }^{180}$.

También hubo situaciones de ocultamiento por parte de familiares de enfermos ante el temor a las consecuencias negativas que podía acarrear el contacto con ellos, resolviéndose el problema con enterramientos clandestinos en las iglesias $^{181}$.

Otro factor de infrarrepresentación fue el subregistro de párvulos; este fenómeno, que afectaba especialmente a los fallecidos menores de un año sobre todo a las niñas, no es exclusivo del periodo epidémico pero con toda seguridad se dio en el periodo 1854-56, en el que hubo poblaciones en las que no se contabilizaban fallecimientos de niños como sucedió en pueblos de las zonas Media y Montaña de Navarra ${ }^{182}$

Pese a que de forma puntual en algunas localidades como Olivenza el número de varones fallecidos fue superior al de las mujeres, 56 frente a $41^{183}$, encontramos que de manera generalizada hubo un mayor número de contagios y fallecimientos entre las mujeres que entre los varones. En Chinchón (Madrid) en 1855 fallecieron por cólera 72 mujeres y solo 43 hombres ${ }^{184}$. En Jijona (Alicante) en la epidemia de 1854 murieron 88 mujeres y solo 50 varones $^{185}$ En Requena (Valencia) durante el brote de 1854 murieron 54 hombres, 71 mujeres y en 1855190 varones y 250 mujeres ${ }^{186}$ En Badajoz durante 1854 la mortalidad femenina sobre el total supuso por parroquias los siguientes porcentajes: San

179. Pilar RODRÍGUEZ FLORES: Epidemia y sociedad en Badajoz..., p. 120.

180. Luis SÁNCHEZ ÁLVAREZ y Diego PERAL PACHECO: "La epidemia de cólera de $1855 \ldots$..., p. 1305

181. José Antonio JIMÉNEZ QUINTERO: “La epidemia de 1854-1855...", p. 32.

182. Eduardo MARTíNEZ LACABE: "La epidemia de cólera de 1855 en Navarra ...", p. 91.

183. José Luis SÁNCHEZ ÁLVAREZ y Diego PERAL PACHECO: "La epidemia de cólera de 1855...", p. 1308.

184. Raúl PANADERO GARCÍA: "Epidemias de cólera en Chinchón...", p. 239.

185. José BERNABÉ RUIZ: "La epidemia de cólera de 1854 en Xixona...".

186. Ignacio LATORRE ZACARÉS: "El cólera en Requena ...", p. 205. 
Andrés 61\%, Concepción 60\%, San Juan 58\% y San Agustín 55\% ${ }^{187}$. En 1856 en la provincia de Badajoz fallecieron 2.107 hombres frente a 2.769 mujeres $^{188}$. En Navarra durante 1855, contando todos los grupos de población las fallecidas fueron un $54,79 \%$ y los varones el $45,21 \%$, incrementándose la sobremortalidad femenina entre los mayores de 20 años hasta hacerse muy acusada ${ }^{189}$. Ya los coetáneos de la epidemia se dieron cuenta de que morían más mujeres, pero como no se conocía cuál era el origen de la enfermedad ni cómo se transmitía era imposible que dieran una explicación certera de las causas que provocaban el fenómeno, por ejemplo Mariano González Samano encontraba la causa de lo que él entendía era una predisposición femenina a contraer al cólera en 2 razones: la debilidad que originaba en el organismo la pérdida de sangre por la menstruación y el temor que provocaba tener un parto en época de epidemia ${ }^{190}$. La explicación más plausible para la sobremortalidad femenina probablemente sea el contacto que muchas mujeres tenían con aguas contaminadas o con ropas de enfermos sucias con restos de heces; por ejemplo en Gerona fallecieron por cólera entre agosto y septiembre de 185454 hombres y 86 mujeres, entre ellas la mayor parte de la lavanderas de los hospitales y de las casas particulares en que hubo enfermos coléricos ${ }^{191}$; esta misma opinión tiene Juan Carlos Bilbao Diez para explicar porqué en la ciudad Logroño durante la oleada de 1854 faIlecieron 263 mujeres, el 64\% del total ${ }^{192}$.

La enfermedad no atacó por igual a todos los grupos sociales. Es una constante que, aunque también personas adineradas la padeciesen, los más pobres, aquellos que vivían en los barrios más humildes, en las casas más insalubres, la sufrieron con mayor intensidad. Por ejemplo durante el brote de 1854 en Cádiz las zonas más afectadas fueron barrios de personas con escaso recursos: el de Santa María y una parte del de La Viña ${ }^{193}$; en la ciudad de Tarragona, tanto durante el brote de 1854 como el de 1855, la mayor parte de los casos se dieron en la parroquia de Sant Joan, del barrio del puerto y la zona alta, junto a la catedral, ambas humildes con casas en malas condiciones higiénicas ${ }^{194}$; el barrio de San Pedro, en la ciudad de Gerona, la zona pobre más populosa y en peores condiciones higiénicas fue la más atacada en el verano de $1854^{195}$.

187. Pilar RODRÍGUEZ FLORES: Epidemia y sociedad en Badajoz..., p. 111.

188. Ibid., p. 128.

189. Eduardo MARTíNEZ LACABE: "La epidemia de cólera de 1855 en Navarra ...", p. 108. 190. Mariano GONZÁLEZ DE SAMANO: Memoria Histórica del ..., vol. I, p. 79.

191. José PORCALLA Y DIOMER: Historia del cólera-morbo epidémico..., p. 25.

192. Juan Carlos BILBAO DíEZ: "La epidemia de cólera de 1855 ...", p. 121.

193. Juan CEBALLOS: Consejos higiénico preservativos..., p. 8.

194. Josep M SABATÉ I BOSCH y Julio Luis QUÍLEZ MATA: "L'epidèmia de còlera a Tarragona l'any 1854-1855", Gimbernat: Revista d'Història de la Medicina i de les Ciències de la Salut, [en línia], 24 (1995), pp. 231-236. Recuperado de Internet (https://www.raco.cat/index. php/Gimbernat/article/view/45049). [consultado 23/01/2020]

195. José PORCALLA Y DIOMER: Historia del cólera-morbo epidémico..., p. 6. 


\section{Conclusiones}

De 1854 a 1856 España se vio asolada por el cólera. Los datos oficiales nos dicen que la epidemia causó 829.189 contagios y 236.744 fallecidos. No caben dudas de que estas cifras reales fueron mayores, en una cuantía imposible de establecer.

La lucha contra la enfermedad fue derivada por el Gobierno hacia las autoridades locales, especialmente los ayuntamientos; éstos tuvieron en la Juntas Municipales de Sanidad y Beneficencia su principal herramienta. La obtención de recursos económicos para hacer frente a las necesidades sanitarias y sociales también recayó en las corporaciones locales; en muchos lugares contaron con el apoyo solidario de sus vecinos.

La labor del Gobierno prácticamente quedó limitada a publicar legislación; la relativa a la prohibición de establecer limitaciones de movilidad fue sistemáticamente incumplida.

Aunque hubo muchos comportamientos dignos de elogio, la epidemia también provocó otros reprobables, como la negación de la existencia de la enfermedad por motivos económicos o la huida de personas imprescindibles en la lucha contra el cólera como alcaldes, concejales o médicos.

\section{Bibliografía}

APONTE MARIN, Ángel y LÓPEZ CORDERO, Juan Antonio: El miedo en Jaén. 3.2. La epidemia de cólera de 1854-1855, Jaén, Diputación Provincial, 2000. Recuperado de Internet (https://www.pegalajar.org/miedo/miedo.htm). [consultado 16/12/2019]

BERNABÉ RUIZ, José: "La epidemia de cólera de 1854 en Xixona" 2020. Recuperado de Internet (https://madeinjijona.com/la-epidemia-de-colera-de1854-en-xixona/). [consultado 21/11/2020]

BILBAO DÍEZ, Juan Carlos: "La epidemia de cólera de 1855 en la ciudad de Logroño", Cuadernos de Investigación: Historia, tomo 10, 1 (1984), pp. 113124.

CARO CANCELA, Diego: "El cólera-morbo en Jerez: la epidemia de 1854", Trocadero, 3 (2011), pp. 117-155. Recuperado de Internet (https://revistas.uca. es/index.php/trocadero/article/view/1039). [consultado 31/10/2020]

CEBALLOS, Juan: Consejos higiénico preservativos del cólera-morbo: discusión sobre su contagio, Cádiz, Imprenta de la Revista Médica, 1855.

FARRERONS NOGUERA, Lourdes: Historia del sistema sanitario español: Debates parlamentarios, 1812-1986, Madrid, Ed. Díaz de Santos, 2013.

FERIA LORENZO, Diego José: “La primera regulación sanitaria en España: la Ley Orgánica de 1855", Revista de Historia das Ideias, 33 (2012), pp. 217-239. 
GONZÁlEZ CASTILLO, Paloma, GÓMEZ GARCíA, María Luz y GONZÁLEZ GALÁN, V.: "La salud pública en las actas municipales de Montijo: 18321855", Revista de Estudios Extremeños, tomo LIX, 1 (2003), pp. 145-160.

GONZÁLEZ DE SAMANO, Mariano: Memoria Histórica del cólera morbo-asiático en España, Madrid, Imprenta de Manuel Álvarez, 1858.

JIMÉNEZ QUINTERO, José Antonio: “La epidemia de 1854-1855", Revista Jábega, 16 (1976), pp. 29-34. Recuperado de Internet (https://www.cedma.es/ catalogo/jabega.php?numero=16) [consultado 17/04/2020]

JUNTA MUNICIPAL DE VALENCIA: Memoria sobre la invasión y curso del cólera morbo asiático en la ciudad de Valencia. Año 1854, Valencia, Imprenta de Jaime Martínez, 1855.

Las instrucciones populares para la prevención del cólera morbo y curación de sus primeros síntomas, Madrid, Real Academia de Medicina de Madrid, 1854.

LATORRE ZACARÉS, Ignacio: "El cólera en Requena, una sociedad frente a la enfermedad", Cuadernos de Geografía, 95-96 (2014), pp. 201-225.

LIETOR MORALES, Juan Antonio, ROJAS LÓPEZ, José y LÓPEZ CORDERO, José: Pegalajar: nueva aproximación histórica, Pegalar (Jaén), Ayuntamiento de Pegalajar, 1994 Recuperado de Internet (https://www.pegalajar.org/nuevaaproximacionhistorica/capitulo_iv_3_5b.htm). [consultado 03/05/2020]

MARTÍNEZ LACABE, Eduardo: "La epidemia de cólera de 1855 en Navarra: demografía y mentalidad", Revista Gerónimo de Uztariz, 12 (1996), pp. 89114.

Memoria de las Juntas Municipales de Sanidad y Beneficencia de Madrid acerca de la epidemia de cólera-morbo padecida en esta capital en el otoño de 1854, Madrid, Oficina Tipográfica de la Junta Municipal de Beneficiencia, 1855.

Memoria de las Juntas Municipales de Sanidad y Beneficencia de Madrid acerca de la epidemia de cólera-morbo padecida en esta capital en el otoño de 1855, Madrid, Oficina Tipográfica de la Junta Municipal de Beneficiencia, 1856.

Memoria que la Junta Parroquial de Beneficencia del distrito de San Francisco publica para dar cuenta de su administración en el tiempo que el cólera morbo asiático afligió a los habitantes de esta capital, Santander, Imprenta y Litografía de Martínez, 1855.

MÉNDEZ ÁlVARO, Francisco: Consideraciones sobre la higiene pública y mejoras que reclama en España la higiene municipal, Madrid, Imprenta de José Rodríguez, 1853.

MONLAU, Pedro Felipe: ¿Qué medidas puede dictar el gobierno a favor de las clases obreras?, Barcelona, Imprenta Politécnica de Tomás Gorchs, 1856. 
PANADERO GARCÍA, Raúl: "Epidemias de cólera en Chinchón durante el siglo XIX", en Concurso de investigación sobre Chinchón y su entorno, pp. 201-255. Recuperado de Internet (https://studylib.es/doc/7519520/epidemias-del-c\%C3\%B3lera-en-chinch\%C3\%B3n-en-el-siglo-xix). [consultado 22/11/2019]

PORCALLA Y DIOMER, José: Historia del cólera-morbo epidémico que invadió la ciudad y partido de Gerona en el año 1854, Barcelona, Imprenta de Tomás Gorchs, 1859.

PUYOL ARANGUREN, Vicente: Examen comparativo de varios tratamientos empleados contra el cólera-morbo asiático, Pamplona, Imprenta de Longas y Ripa, 1855.

RODRIGUEZ FLORES, Pilar: Epidemia y sociedad en Badajoz (1854-1866), Badajoz, Diputación Provincial de Badajoz, 1996. Recuperado de internet (http://www.cervantesvirtual.com/nd/ark:/59851/bmc891t9). [consultado 28/10/2020]

ROURE, Conrad: Recuerdos de mi larga vida, Barcelona, s.e., 1925. Recuperado de internet (http://www.xtec.cat/ jrovira6/isabel21/colera54.htm) [consultado 17/11/2020]

SABATÉ I BOSCH, Josep M., QUÍLEZ MATA, Julio Luis: "L'epidèmia de còlera a Tarragona I'any 1854-1855", Gimbernat: Revista d'Història de la Medicina i de les Ciències de la Salut, [en línia], 24 (1995), pp. 231-236. Recuperado de Internet (https://www.raco.cat/index.php/Gimbernat/article/view/45049). [consultado 23/01/2020]

SÁNCHEZ ÁLVAREZ, José Luis y PERAL PACHECO, Diego: "La epidemia de cólera de 1855 en Olivenza", Revista de Estudios Extremeños, Tomo XLV, 3 (2009), pp. 1289-1320.

URQUIJO Y GOITIA, José Ramón: "Condiciones de vida y cólera: la epidemia de 1854-1856 en Madrid", Estudios de Historia Social, 15 (1980), pp. 63139.

URQUIJO Y GOITIA, José Ramón: "Madrid ante la epidemia de cólera de 185456", Asclepio, XXXV (1983), pp. 27-52.

VALENZUELA GUZMÁN, Magdalena: "1855. Epidemia de cólera en Huelma. El verano del terror", Sumuntan: anuario de estudios sobre Sierra Mágina, 32 (2014), pp. 237-248.

VIÑES RUEDA, José Javier: La sanidad española en la segunda mitad del siglo XIX, Navarra, Gobierno de Navarra, 2006.

Publicaciones Periódicas:

- Anales de Homeopatía (Madrid)

- Boletín Oficial de la provincia de Badajoz (Badajoz) 
- Boletín Oficial de la provincia de Guadalajara (Guadalajara)

- Boletín Oficial de la provincia de Madrid (Madrid)

- Boletín Oficial de la provincia de Orense (Orense)

- Boletín oficial de la provincia de Segovia (Segovia)

- Boletín Oficial del Ministerio de Hacienda (Madrid)

- El Clamor Público (Madrid)

- El Coruñés (La Coruña)

- La España (Madrid)

- El Faro de Vigo (Vigo)

- La Gazeta de Madrid (Madrid)

- El Genio de la libertad (Palma)

- El Porvenir Médico (Madrid)

- El Siglo Médico (Madrid) 